Check for updates

Cite this: J. Mater. Chem. C, 2017, 5, 9053

Received 26th July 2017,

Accepted 15th August 2017

DOI: $10.1039 / \mathrm{ctc03357e}$

rsc.li/materials-c

\title{
Spin-dimer networks: engineering tools to adjust the magnetic interactions in biradicals $\dagger$
}

\author{
Yulia B. Borozdina, ${ }^{\text {ab }}$ Evgeny A. Mostovich, ${ }^{\text {ac }}$ Pham Thanh Cong, ${ }^{d}$ Lars Postulka, \\ Bernd Wolf, ${ }^{d}$ Michael Lang ${ }^{d}$ and Martin Baumgarten (D) *a
}

\begin{abstract}
Magneto-structural correlations in stable organic biradicals have been studied on the example of weakly exchange coupled models with nitronyl nitroxide and imino nitroxide spin-carrying entities. Here, heteroatom substituted 2,2'-diaza- and 3,3'-diaza-tolane bridged biradicals were compared with the hydrocarbon analogue, while a biphenyl model with its 2,2'-bipyridine counterpart. For a 3,3'-diazatolane bridge the torsional angle between the nitronyl nitroxides and the pyridyl rings increased heavily $\left(\sim 52-54^{\circ}\right)$ leading to a smaller theoretical intra-dimer exchange coupling value. However, a very large antiferromagnetic coupling was obtained experimentally. This could be appropriately explained by the presence of dominating inter-dimer exchange between the molecules. For the bis(imino nitroxide) with tolane bridge a field induced ordered state between 1.8 to $4.3 \mathrm{~T}$ in AC-susceptibility measurements was observed. In terms of a Bose Einstein condensate (BEC) of triplons this phenomenon could be described as a magnetic field induced ordered phase with 3D character.
\end{abstract}

\section{Introduction}

Magnetic dimers formed by weakly interacting antiferromagnetically coupled spin $S=1 / 2$ centres are recognized as suitable candidates for exploring critical phenomena under well-controlled conditions. ${ }^{1}$ When these systems are placed in a magnetic field strong enough to close the dimer gap, a gas of triplet excitations (triplons) is formed. ${ }^{1}$ Depending on the topology of the dimerdimer couplings, various scenarios can be observed. Prominent examples include the Bose-Einstein condensation (BEC) of triplons in three-dimensionally-coupled dimer systems, as described by Tchernyshyov et al., ${ }^{2}$ and the Luttinger-liquid behavior revealed in a one-dimensional spin-ladder system by Krämer and co-workers. ${ }^{3}$ More recently, a Berezinskii-Kosterlitz-Thouless scenario was observed by Tutsch et al. in a two-dimensional coordinated copper polymer with large interlayer spacing. ${ }^{4}$

\footnotetext{
${ }^{a}$ Max Planck Institute for Polymer Research, Ackermannweg 10, 55128 Mainz, Germany.E-mail: martin.baumgarten@mpip-mainz.mpg.de

${ }^{b}$ Institute of Biochemistry, Ernst-Moritz-Arndt University Greifswald, Felix-Hausdorff-Straße 4, 17487 Greifswald, Germany

${ }^{c}$ Novosibirsk Institute of Organic Chemistry Siberian Branch of the Russian Academy of Science, Lavrentiev avenue 9, 630090 Novosibirsk, Russia

${ }^{d}$ Physikalisches Institut, Johann Wolfgang Goethe-University Frankfurt, 60438 Frankfurt am Main, Germany

$\dagger$ Electronic supplementary information (ESI) available: Selected spectroscopic data, additional crystallographic data, structural details and magnetic susceptibility plots of 1d, 3d, 4d and 5d (pdf). CCDC 823716, 816632, 816630, 823717, 858078 and 810139. For ESI and crystallographic data in CIF or other electronic format see DOI: 10.1039/c7tc03357e
}

In general, organic magnetic materials possess properties not shown by traditional inorganic compounds. ${ }^{5-8}$ Plasticity, flexibility and solubility in common organic solvents define the ease of various device fabrication. Advanced chemistry techniques permit small structural modifications in already achieved model systems in order to fine-tune their physical properties. In addition, organic-based magnetic materials offer a number of convenient tools extremely helpful in controlling the intra- and inter-dimer exchange coupling, such as $\pi-\pi$ interactions, hydrogen bonding, etc. Nitronyl nitroxide (NN) radicals are well-known for their stability and bidentate character. ${ }^{9,10} \mathrm{NN}$ radicals are among the most popular spin carriers used to construct molecule-based magnets. $^{10}$

Importantly, in these radicals the spin density of the unpaired electron is delocalized over two semi-equivalent sites of coordination. This in turn allows the arrangement of the NN-molecules into a supramolecular network of interacting spins. ${ }^{11}$ Theoretical studies emphasized the importance of the mutual orientation and the relative distances in the crystal packing for promoting an efficient magnetic coupling. ${ }^{11,12}$ As was mentioned by Lahti, ${ }^{13}$ minor changes in the crystal packing of biradicals could result in significant alterations of the magnetic behavior in the bulk material. In this regard the influence of the $\pi$-bridges on the intra- and intermolecular exchange interactions in conjugated biradical networks was studied on the example of the diazotolane dinitroxide models (Fig. 1). It was anticipated that heteroatom substitution could offer a particularly effective pathway for transmitting the magnetic interactions. $^{14}$ 


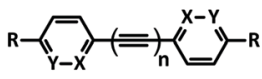

$1 \mathrm{n}=1, X=\mathrm{N}, \mathrm{Y}=\mathrm{C}$

$2 \mathrm{n}=1, X=\mathrm{C}, \mathrm{Y}=\mathrm{N}$

$3 \mathrm{n}=0, \mathrm{X}, \mathrm{Y}=\mathrm{C}$

$4 n=0, X=N, Y=C$

$5 n=1, X, Y=C$ (a)

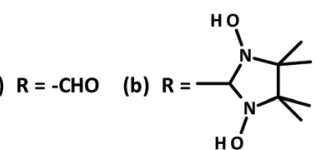

(c) $R$

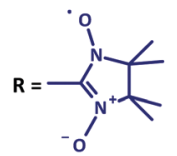

(d)

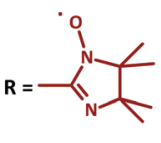

Fig. 1 Structure of biradical model systems 1-5

Typically, imino nitroxides (INs) reveal a reduced $J_{\text {dimer }}$ value when compared to the corresponding NN biradicals. Taking this fact into consideration, already known bridges could be used, where otherwise a strong intramolecular exchange coupling was observed. ${ }^{11}$ Following this strategy, three bisimino nitroxides 3d, $\mathbf{4 d}, \mathbf{5 d}$ were prepared (Fig. 1). ${ }^{15}$

In the current work we report the synthesis of a series of new nitroxide biradicals (Fig. 1), their characterization, including X-ray structural analysis and their magnetic properties, which are discussed with respect to the quantum chemical calculations based on the DFT approach.

\section{Results and discussion}

\section{Synthesis of nitroxide biradicals}

Access to the family of diazatolane biradicals $1 \mathrm{c}$ and $2 \mathrm{c}$ required the synthesis of key precursors 1a and 2a, which were prepared following Sonogashira-Hagihara methodology. ${ }^{16}$ Interestingly, both structural isomers 1a and 2a could be achieved starting from the same precursor, i.e. commercially available 2,5-dibromopyridine 6 (Scheme 1). Depending on the reaction conditions (such as solvent, base) compound 6 could be selectively monolithiated. ${ }^{17-21}$ More precisely, reaction times and solvents played a crucial role in the course of electrophilic substitution, leading to predominant formation of the organolithium intermediate at the 2 or 5 position. ${ }^{22,23}$ In order to drive the reaction in the course of kinetically more favorable 2-bromo-5-carbaldehydepyridine 7 , it was carried out in dry diethyl ether at $-78{ }^{\circ} \mathrm{C}$, and DMF was added to the mixture 20 min after the addition of $n$-BuLi was complete (Scheme 1).

According to the preliminary results obtained by our group, 2-ethynyl-5-formyl-pyridine was unstable. Therefore, at first aldehyde 7 was transformed into 2-bromo-5-[1,3]dioxolan-2-ylpyridine 8 following the standard protocol. ${ }^{24}$ Compound 8 was involved in Pd-catalyzed Sonogashira-Hagihara coupling with trimethylsilyl acetylene (TMSA) giving rise to derivative 9 . Hydrolysis of the trimethylsilyl group using $1 \mathrm{~N} \mathrm{NaOH}$ solution in a deaerated THF-water mixture $(1: 1)$ granted the NMR-pure ethynyl derivative 10, which was used further without additional purification.

Sonogashira-Hagihara coupling reactions can be successfully carried out under various conditions. ${ }^{16}$ For our systems it was found that by decreasing the reaction temperature from $80{ }^{\circ} \mathrm{C}\left(\mathrm{DMF} / \mathrm{Et}_{3} \mathrm{~N}, 1: 1\right)$ to $\sim 22{ }^{\circ} \mathrm{C}\left(\mathrm{CH}_{3} \mathrm{CN} / \mathrm{Et}_{3} \mathrm{~N}, 1: 1\right)$ the formation

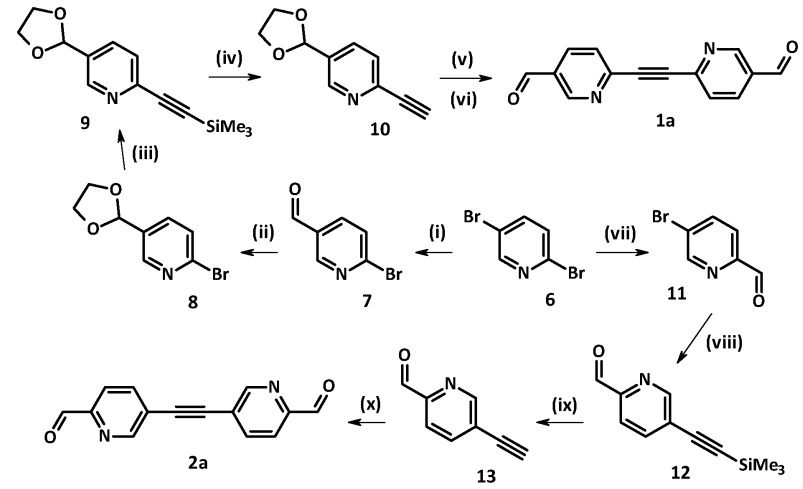

Scheme 1 Synthesis of dialdehydes $\mathbf{1 a}$ and $\mathbf{2 a}$. Reagents and conditions: (i) (a) $n$-BuLi, $\mathrm{Et}_{2} \mathrm{O},-78{ }^{\circ} \mathrm{C}$, under $\mathrm{Ar}, 45 \mathrm{~min}$, (b) $\mathrm{DMF},-78{ }^{\circ} \mathrm{C}$, under $\mathrm{Ar}$, $105 \mathrm{~min}$, (c) $\mathrm{HCl}(3 \%), 20$ min; (ii) ethyleneglycol, $p$ - TsOH, benzene, reflux, $20 \mathrm{~h}$; (iii) TMSA, $\mathrm{Pd}\left(\mathrm{PPh}_{3}\right)_{2} \mathrm{Cl}_{2}, \mathrm{Cul}_{1} \mathrm{PPh}_{3}, \mathrm{DMF}, \mathrm{Et}_{3} \mathrm{~N}$, heating at $80{ }^{\circ} \mathrm{C}$ under Ar, $14 \mathrm{~h}$; (iv) $1 \mathrm{M} \mathrm{NaOH}, \mathrm{H}_{2} \mathrm{O}-\mathrm{THF}, 5{ }^{\circ} \mathrm{C}, 35 \mathrm{~min}$; (v) 8, $\mathrm{Pd}\left(\mathrm{PPh}_{3}\right)_{2} \mathrm{Cl}_{2}, \mathrm{Cul}$, $\mathrm{PPh}_{3}, \mathrm{CH}_{3} \mathrm{CN}, \mathrm{Et}_{3} \mathrm{~N}$, at rt under $\mathrm{Ar}, 18 \mathrm{~h}$; (vi) $p-\mathrm{TsOH}, \mathrm{H}_{2} \mathrm{O}$-acetone, $84 \mathrm{~h}$; (vii) (a) $n$-BuLi, toluene, $-78{ }^{\circ} \mathrm{C}$, under $\operatorname{Ar} 2 \mathrm{~h}$, (b) DMF, $-78{ }^{\circ} \mathrm{C}$, under $\mathrm{Ar}, 2$ h, (c) $\mathrm{NH}_{4} \mathrm{Cl}, 30 \mathrm{~min}$; (viii) TMSA, $\mathrm{Pd}\left(\mathrm{PPh}_{3}\right)_{2} \mathrm{Cl}_{2}, \mathrm{Cul}, \mathrm{PPh}_{3}, \mathrm{DMF} \mathrm{Et}_{3} \mathrm{~N}$, heating at $80{ }^{\circ} \mathrm{C}$ under $\mathrm{Ar}, 16 \mathrm{~h}$; (ix) $\mathrm{K}_{2} \mathrm{CO}_{3}, \mathrm{MeOH}$, under $\operatorname{Ar} 90 \mathrm{~min}$; (x) 11, $\mathrm{Pd}\left(\mathrm{PPh}_{3}\right)_{2} \mathrm{Cl}_{2}, \mathrm{Cul}, \mathrm{PPh}_{3}, \mathrm{DMF}, \mathrm{Et}_{3} \mathrm{~N}$, heating at $80^{\circ} \mathrm{C}$ under $\mathrm{Ar}, 12 \mathrm{~h}$.

of several side-products was prevented. Therefore, the attachment of bromo derivative $\mathbf{8}$ to the pre-organized ethynyl-pyridine $\mathbf{1 0}$ was carried out at room temperature in the $\mathrm{CH}_{3} \mathrm{CN} / \mathrm{Et}_{3} \mathrm{~N}$ solvent mixture, which led to the corresponding product in a reasonable yield $(72 \%)$. Notably, our attempts to remove dioxolane protective groups in the presence of dilute $\mathrm{HCl}(3 \%)$ resulted in precipitation of the acid by the triple bond. Thus, the final step towards 1a was performed under milder conditions. To a solution of the dioxolane precursor in an acetone-water mixture $(7: 1)$ a catalytic amount of $p$-TsOH acid $(2 \mathrm{~mol} \%)$ was added. ${ }^{24}$ Upon stirring the reaction mixture for 3 days at room temperature the target $2,2^{\prime}$-diazatolane $4,4^{\prime}$-dialdehyde 1 a was obtained in nearly quantitative yield (81\%).

The isomeric $3,3^{\prime}$-diazatolane dialdehyde $\mathbf{2 a}$ was obtained in a similar way (Scheme 1). Here, 2,5-dibromo-pyridine 6 was selectively monolithiated in position 2 in toluene media. Time of the exchange reaction with $n$-BuLi was increased to $90 \mathrm{~min}$ to ensure the desired organolithium intermediate formation, and precursor 11 was obtained in $49 \%$ yield. ${ }^{21}$ Next, standard Sonogashira-Hagihara methodology ${ }^{16}$ was employed. Final separation on a silica gel column with a hexane/EtOAc eluent mixture (3:2) yielded 5,5'-ethyne-1,2-diylbis(pyridine-2-carbaldehyde) $2 \mathrm{a}$ in decent yield (69\%).

Several synthetic procedures towards compound 3a were reported in the literature. ${ }^{15}$ Inspired by the efficiency and simplicity of the approach sketched in Scheme 2, commercially available 4,4'-dibromobiphenyl 14 was treated with $n$-BuLi in the presence of a catalytic amount of TMEDA. After addition of dry DMF, typical work-up and purification, biphenyl dialdehyde 3a was isolated in $58 \%$ yield.

Bipyridine-4,4'-dicarbaldehyde $4 a$ was achieved upon formation of 5,5'-bis-(bromo-methyl)-2,2'-bipyridine $\mathbf{1 6}$ from the corresponding dimethyl-bipyridine precursor $\mathbf{1 5}$ following the procedure described by Vögtle. ${ }^{25}$ Then nucleophilic substitution under Sommelet 


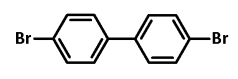

14

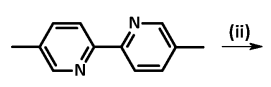

15

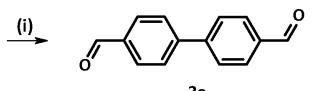

3a

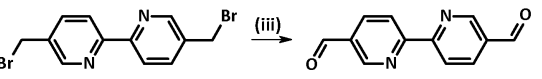

16

4a
Scheme 2 Synthesis of dialdehydes $3 \mathbf{a}$ and $\mathbf{4 a}$. Reagents and conditions: (i) (a) $n$-BuLi, THF, TMEDA, under $\mathrm{Ar},-78{ }^{\circ} \mathrm{C} 30 \mathrm{~min},-50{ }^{\circ} \mathrm{C} 30 \mathrm{~min}$; (b) DMF, $-78^{\circ} \mathrm{C}$, under $\mathrm{Ar}, 1 \mathrm{~h}$, (c) $\mathrm{NH}_{4} \mathrm{Cl}, 20 \mathrm{~min}$; (ii) $\mathrm{NBS}, \mathrm{CCl}_{4}$, benzoyl peroxide, reflux under Ar, 14 h; (iii) hexamethylenetetramine, $\mathrm{EtOH}-\mathrm{H}_{2} \mathrm{O}$, reflux, $60 \mathrm{~h}$.

conditions led to $\mathbf{4 a} .^{26}$ Synthesis of tolane dialdehyde $\mathbf{5 a}$ was described elsewhere. ${ }^{11}$

Final steps in the synthesis of nitroxides included condensation between 2,3-bis(hydroxyamino)-2,3-dimethylbutane (BSA) with an aldehyde, followed by the oxidation of the condensation products (i.e. imidazolidine derivatives 1-5b). ${ }^{11,15}$ Typically, the first reaction was performed under strictly anaerobic conditions in refluxing toluene (Scheme 3). Here, the corresponding $N, N^{\prime}$ dihydroxyimidazolidines $\mathbf{1 b}, \mathbf{3 b}, \mathbf{4 b}$, and $\mathbf{5 b}$ were obtained in quantitative yields. As an exception synthesis of diazotolane imidazolidine $\mathbf{2 b}$ was realized in absolute degassed methanol at room temperature.

In order to avoid further oxidation, and, therefore, to diminish the loss of the radical units, oxidation of $N, N^{\prime}$-dihydroxyimidazolidine intermediate $\mathbf{1} \mathbf{b}$ with sodium periodate was carried out at $\sim 0-5{ }^{\circ} \mathrm{C}$ using an ice bath. ${ }^{27}$ The progress of the reaction could be conveniently monitored by TLC analysis of the reaction mixture aliquots. Synthesis of derivative $2 \mathbf{c}$ was achieved using an excess of $\mathrm{MnO}_{2}$ in methanol. Imino biradicals 1d, 3d, and 4d were obtained following the procedure described by Tretyakov et al. ${ }^{28,29}$ This method helped to avoid the harmful usage of acids and to synthesize the target molecules in better yields. As an illustration, transformation of imidazolidine $\mathbf{1 b}$ into the corresponding imino biradical 1d with an excess of $\mathrm{MnO}_{2}$ in $\mathrm{CH}_{3} \mathrm{NO}_{2}$ media is depicted in scheme 3. To aid the interpretation of magnetic properties of the isomeric NN 1c and 2c related IN biradical 1d was also prepared.

The UV-Vis absorption spectra of $1 \mathbf{c}$ and $2 \mathrm{c}$ with maxima around $600 \mathrm{~nm}$ were typical for the nitronyl nitroxides, while the red bisiminonitroxides absorbed around $460 \mathrm{~nm}$ (Table S2, ESI $\dagger$ ). The EPR spectra of bisnitronylnitroxides exhibited nine lines with $A_{n} / 2$ spacing for four equivalent nitrogens with two

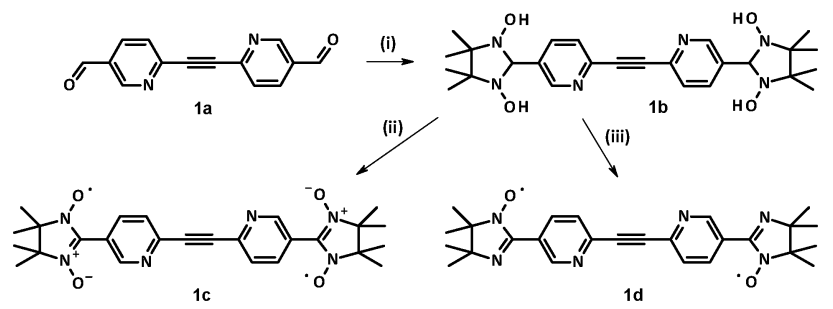

Scheme 3 Synthesis of nitroxide biradicals $1 \mathrm{c}$ and 1d. Reagents and conditions: (i) $\mathrm{BSA}$, toluene, reflux under $\mathrm{Ar}, 4-6 \mathrm{~h}$; (ii) $\mathrm{NalO}_{4}, \mathrm{CH}_{2} \mathrm{Cl}_{2}-$ $\mathrm{H}_{2} \mathrm{O}, 0-5{ }^{\circ} \mathrm{C}, 30-40 \mathrm{~min}$; (iii) $\mathrm{MnO}_{2}, \mathrm{CH}_{3} \mathrm{NO}_{2}, 35 \mathrm{~min}$. strongly coupled radicals. The bisiminonitroxides $(\mathbf{1 d}, \mathbf{3 b}, \mathbf{4 b}, \mathbf{5 d})$ featured 13 lines, corresponding to the inequivalent nitrogens of the imidazoline ring (as presented in the Graphical abstract and Table S2, ESI $\dagger$ ).

\section{Crystal structure analysis}

Crystals were obtained by slow diffusion of hexane in dichloromethane solutions of the nitroxide biradicals at room temperature. Deep-blue needle crystals of nitronyl nitroxides $1 \mathrm{c}$ and $2 \mathrm{c}$ and red blocks of imino nitroxides $\mathbf{1 d}, \mathbf{3 d}, \mathbf{4 d}$, and $\mathbf{5 d}$ were then characterized using X-ray diffraction analysis. Selected torsion angles are reported in Table 1 (with some additional structural data given in the $\mathrm{ESI} \dagger$ ).

All nitroxide biradicals 1c, 2c, 1d, 3d, 4d, and 5d under study possess a planar backbone - the necessary prerequisite for the propagation of weak intramolecular magnetic interactions. Importantly, in such biradical models the torsion angles $\theta$ (see Table 1) play a central role in the modulation of magnetic exchange interactions.

Not surprisingly, similar torsion angles $\theta$ of about $\sim 24^{\circ}$ result in a nearly identical degree of conjugation. ${ }^{11,15}$ Consequently, a comparable spin polarization and close values of the exchange integrals were expected for most of the obtained biradical models (see for comparison Table 1). In contrast to the described situation, the radical units in nitronyl nitroxide $2 \mathrm{c}$ were far more twisted $\left(>50^{\circ}\right)$. From this crystal structure analysis it was assumed that nitronyl biradical $2 \mathrm{c}$ would exhibit a unique behavior among the compounds investigated here.

Biradical 1c adopts a triclinic space group with an inversion centre residing in the middle of the acetylene bridge (Fig. 2). Remarkably, in the asymmetric unit there are two crystallographically independent molecules with a nearly equal geometry. The dihedral angles of the mean plane of the imidazolidine ring and the two coplanar pyridine rings were found to be $\approx 25^{\circ}$ for O1-N2-C7 (O2N3-C7) towards $\mathrm{C} 5$ and $22^{\circ}$ for O3N5-C20 (O4-N6-C20) towards C18 (see Table 1). Here, the $\mathrm{N}(2)-\mathrm{O}(1)$ 1.280(1), $\mathrm{N}(3)-\mathrm{O}(2) 1.278(2), \mathrm{N}(5)-\mathrm{O}(3)$ 1.279(1), and $\mathrm{N}(6)-\mathrm{O}(4)$ 1.272(2) $\AA$ bond lengths occur in the typical range for the nitroxides. ${ }^{11,14,15}$ The $\mathrm{N}(2)-\mathrm{C}(7)$ 1.355(2), N(2)-C(11) 1.503(1), $\mathrm{N}(3)-\mathrm{C}(7)$ 1.351(1), $\mathrm{N}(3)-\mathrm{C}(8)$ 1.503(2), N(5)-C(20) 1.358(2), $\mathrm{N}(5)-\mathrm{C}(24)$ 1.502(1), N(6)-C(20) 1.354(2), and N(6)-C(21) 1.497(1) bond distances are elongated due to the short intermolecular contacts that stabilize the crystal packing (for instance, the ones formed by $\mathrm{N}(6) \mathrm{O}(4))$.

Table 1 Selected bond lengths and dihedral angles for the synthesized biradicals

\begin{tabular}{llll}
\hline & Biradical & $d, \AA$ & $\theta$, deg \\
\hline & 1c & $1.4513(15)$ on C18 & $21.62(9)$ \\
& 2c & $1.4564(15)$ on C5 & $24.84(10)$ \\
& 1d & $1.472(18)$ & $53.72(11)$ \\
& 3d & $1.4743(12)$ on C25 & $23.16(12)$ \\
& 4d & $1.471(2)$ & $24.85(9)$ \\
& 5d & $1.473(2)$ & $15.2(2) \mathrm{O} 1$ \\
& & $1.4754(17)$ & $13.57(19)$ on C5 $\mathrm{O} 2$ \\
\end{tabular}



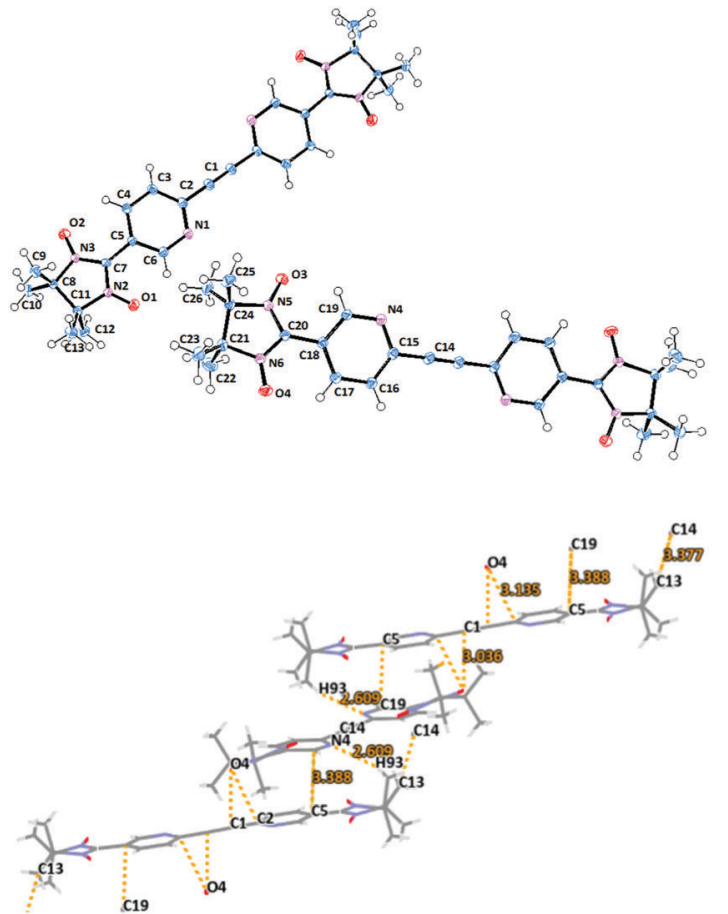

Fig. 2 Molecular structure (top) of biradical 1c with ORTEP drawn at the $50 \%$ probability level and crystal packing (bottom) with emphasized short contacts.

The intermolecular contacts between NO groups of the first molecule with the pyridine rings $\left(\mathrm{O}_{4} \cdots \mathrm{C}^{\prime}{ }^{\prime} 3.036, \mathrm{O} 4 \cdots \mathrm{C} 2^{\prime}\right.$ $3.135 \AA$ ) of the neighboring biradical lead to V-shaped alignment of dimers (Fig. 2 and Fig. S1, ESI $\dagger$ ).

Biradical 2c crystallizes in the $P 2_{1} / c$ space group and its molecular structure is shown in Fig. 3. Compound $2 \mathrm{c}$ features a transoid arrangement with an inversion center of symmetry located in the $\mathrm{C} 1-\mathrm{C}^{\prime}$ bond, which is typical for the derivatives containing acetylene bridges (Fig. 3). In general, the structural data of $2 \mathbf{c}$ are rather similar to those described for the other nitronyl nitroxide biradicals in the literature (Table 1 and Table S1, $\mathrm{ESI} \dagger) .{ }^{11,14}$ A remarkable difference is found in the largely increased torsion between the pyridyl ring and the imidazolidine fragment O1-N2-C7 (O2-N3-C7) with a dihedral angle of 53.72(11) (Fig. 3).

The crystal packing of $2 \mathrm{c}$ presents a beautiful example where the bidentate character of the nitronyl nitroxide fragment plays a major role in the spatial arrangement of the biradical chains. Here, the molecules of $2 \mathrm{c}$ form infinite zig-zag ribbons along the $b$ axes (Fig. 3 and Fig. S3, ESI $\dagger$ ). Notably, the neighboring molecules are organized in an alternate fashion, placing NN groups next to the pyridine plane and, thereby, stabilizing the crystal packing (Fig. S3, ESI $\dagger$ ).

Imino biradical 1d crystallizes in the triclinic space group $P \overline{1}$. There are two independent centrosymmetric half molecules in the asymmetric unit cell. (Fig. 4). The main structural characteristics are similar to those described for the corresponding nitronyl nitroxide derivative 1c. Thus, the pyridine rings form angles of $\approx 23^{\circ}$ and $\approx 25^{\circ}$ with the imidazolidine plane (Table 1). The $\mathrm{N}(2)-\mathrm{O}(1) 1.269(1), \mathrm{N}(221)-\mathrm{O}(211) 1.277(2)$,
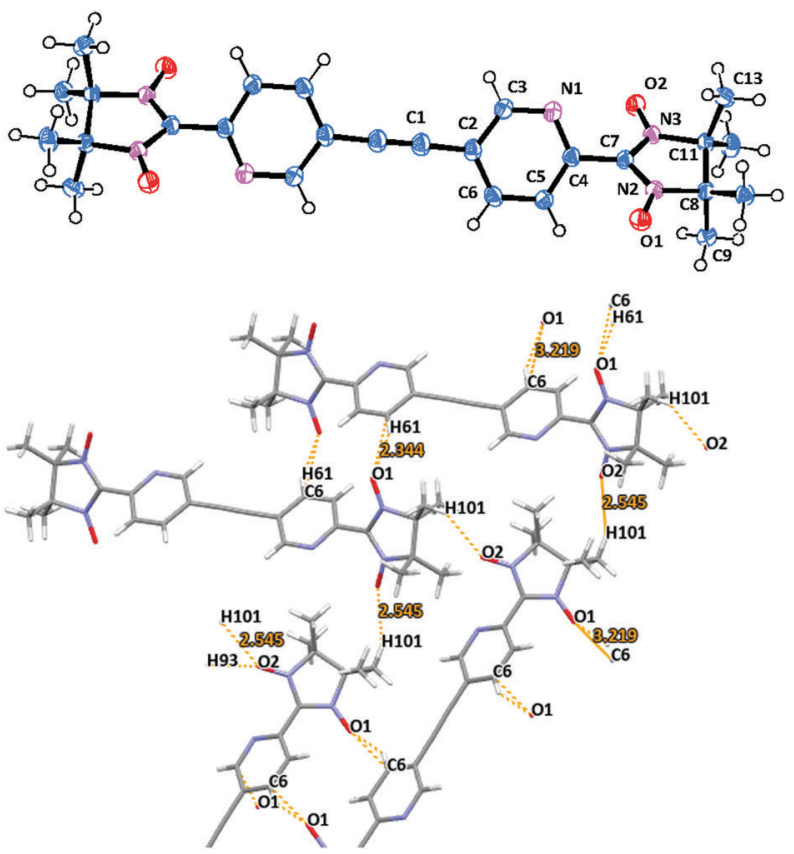

Fig. 3 Molecular structure (top) and crystal packing (bottom) of biradical 2c (view along the a axes).

and $\mathrm{N}(222)-\mathrm{O}(212) 1.257(5) \AA$ bond distances featured minor differences.

The packing arrangement of radical dimers $\mathbf{1 d}$ is shown in Fig. 4, and can be described as a ladder-like structure with biradicals of the first kind forming a stair, and nitroxides of the second type extending from both sides of each step (Fig. S4, $\mathrm{ESI} \dagger)$. The structure is supported by numerous hydrogen bonds

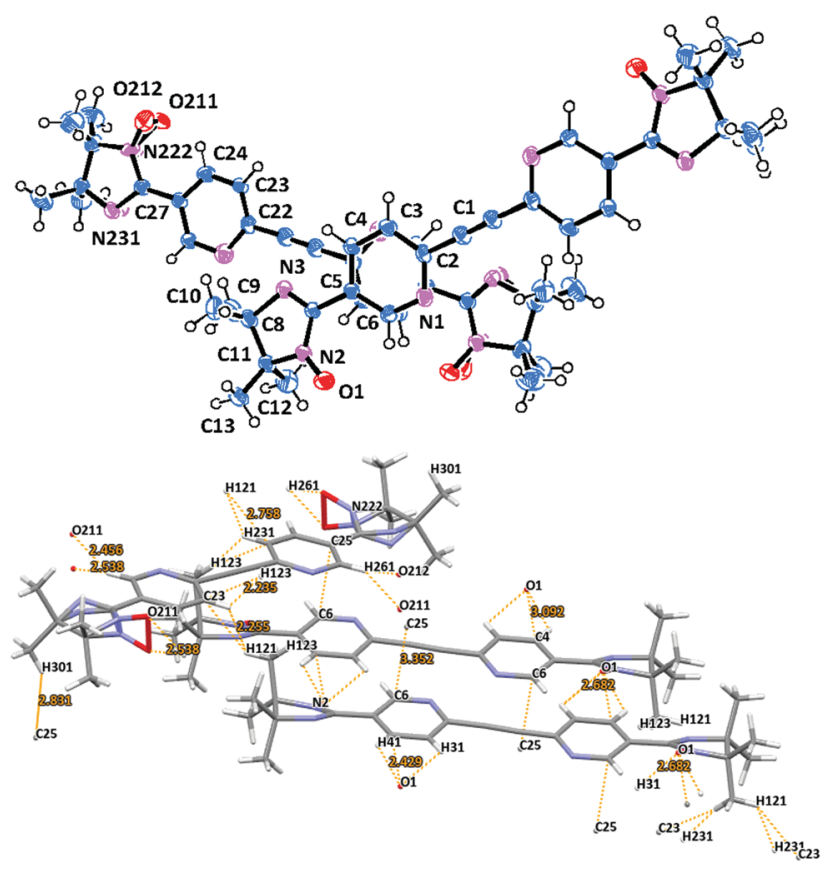

Fig. 4 Molecular structure (top) with two biradical molecules per asymmetric unit of biradical $\mathbf{1 d}$ and short contacts and $\pi$-stacking specified in fragments of molecules from crystal packing. 
arising from the pyridine $\pi$-bridges and the imino nitroxide chelating units. The short contacts of the NO groups and the hydrogen atoms of the pyridine core $\mathrm{O} 211 \cdots \mathrm{H} 261^{\prime}=2.456$, $\mathrm{O} 212 \cdots \mathrm{H} 261^{\prime}=2.538 \AA$ (Fig. 4) seems to be the most important. The shortest interchain distances of $3.352 \AA$ (C6 ‥C2 $\left.25^{\prime}\right)$ are found between the two neighboring diazatolane bridges (Fig. 4). The closest intermolecular contacts between NO groups and a pyridine ring are slightly larger, and are within the range

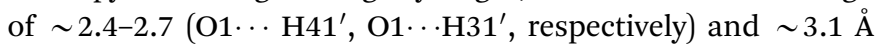
$\left(\mathrm{O} 1 \cdots \mathrm{C} 4^{\prime}\right)$.

Imino biradicals $\mathbf{3 d}$ and $4 \mathbf{d}$ feature isomorphic crystal structures. Thus, they possess the $P 2_{1} / n$ space group with a center of symmetry located in the middle of the aromatic $\mathrm{C}-\mathrm{C}^{\prime}$ bond (Fig. 5 and Fig. S4, ESI $\dagger$ ). The biphenyl bridge in $\mathbf{3 d}$ is surprisingly planar, and the dihedral angle between the mean plane of the benzene ring and the imidazolidine moiety is only $20.2^{\circ} .3 \mathrm{~d}$ is slightly disordered, since the five membered ring can flip around $180^{\circ}$ such that the two NO groups could be oriented ' $E$ ' or ' $Z$ ' with $50 \%$ probability. The $\mathrm{N}(1)-\mathrm{O}(1) 1.226(3)$ and $\mathrm{N}(2)-\mathrm{O}(2) 1.213(3) \AA$ bond lengths are in the standard range. ${ }^{15}$

Naturally, for the isomorphic imino nitroxide derivatives 3d and $\mathbf{4 d}$ the main structural characteristics are very similar. ${ }^{14,27}$ Thus, in 4d the $\mathrm{O}-\mathrm{N}-\mathrm{C}-\mathrm{N}-\mathrm{O}$ moiety is planar, with the $\mathrm{N}(3)-\mathrm{O}(2)$ bond being slightly shorter than $\mathrm{N}(2)-\mathrm{O}(1)$ 1.167(4) and $1.215(3) \AA$, respectively (Fig. S4, ESI $\dagger$ ). Furthermore, in the asymmetric unit of $\mathbf{4 d}$ there are two crystallographically independent forms with the ratio of $\sim 2: 3$ belonging to different biradical chains (Fig. S4, ESI†).

An important feature already mentioned for the other biradicals of the current series is the abundance of close intermolecular contacts between the $\mathrm{N}-\mathrm{O}$ entities and the aromatic moieties in the asymmetric unit. In particular, the hydrogen bonding $\mathrm{O} 1 \cdots \mathrm{H} 31^{\prime} \quad 2.580, \mathrm{O} 1 \cdots \mathrm{H} 123^{\prime} \quad 2.696$, and $\mathrm{O} 1 \cdots \mathrm{C} 3^{\prime} 3.177 \AA$ between the neighboring oxygen atoms and phenyl rings in 3d defines the formation of ribbon-like structures which are
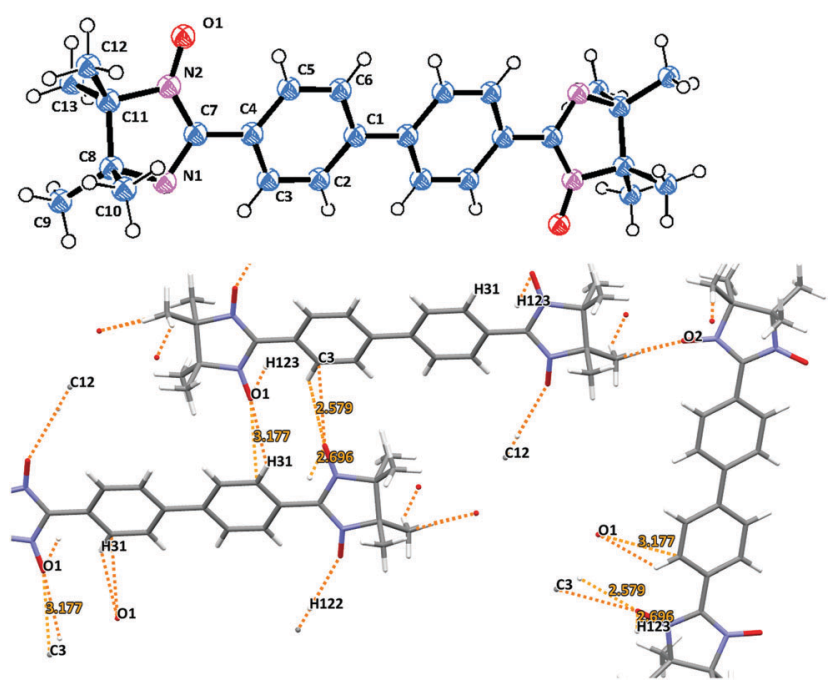

Fig. 5 Molecular structure (top) and crystal packing (bottom) of biradical $3 d$.
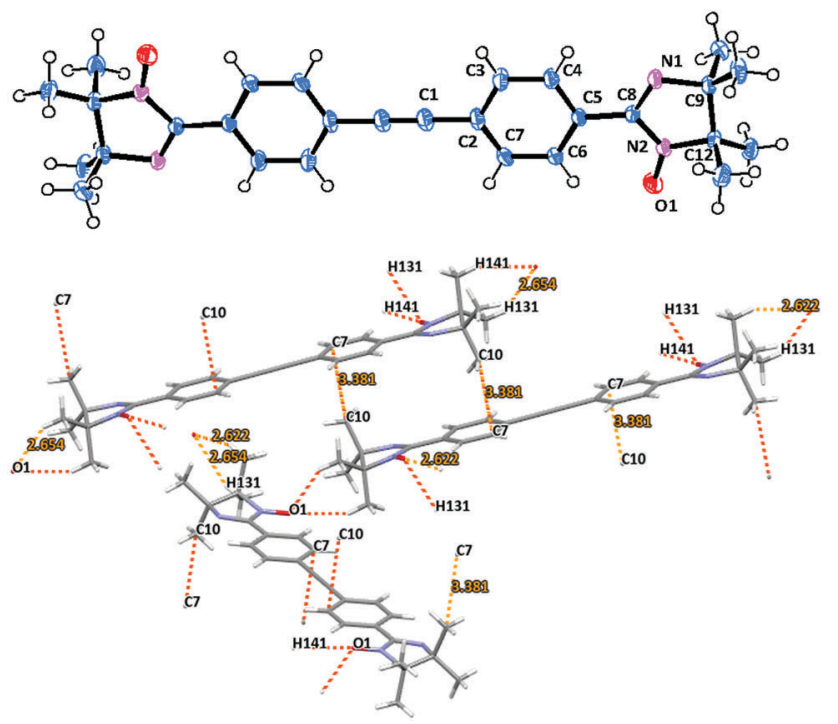

Fig. 6 Molecular structure (top) and crystal packing (bottom) of biradical $5 d$.

further organized in a zig-zag pattern. Likewise, multiple oxygen contacts (i.e. $\mathrm{O} 1 \cdots \mathrm{H} 91^{\prime} \quad 2.302, \mathrm{O} 2 \cdots \mathrm{H}_{5} 1^{\prime} \quad 2.473, \mathrm{O} 2 \cdots \mathrm{H}^{\prime} 3^{\prime}$ $2.600, \mathrm{O} 1 \cdots \mathrm{C} 9^{\prime} 3.199$ and $\mathrm{O} 2 \cdots \mathrm{C}^{\prime} 3.085 \AA$ ) accompany the molecular ordering in the case of imino derivative 4d (Fig. S4, ESI†). Notably, the neighboring chains in $\mathbf{4 d}$ are connected with close $\mathrm{O} 2 \cdots \mathrm{O} 2^{\prime} 2.801 \AA$ A contacts.

Imino nitroxide biradical 5d crystallizes in a monoclinic space group with $P 2_{1} / n$ symmetry. The structure of compound 5d is shown in Fig. 6. In contrast to the previously described biradicals compound $\mathbf{5 d}$ has surprisingly small torsion angles between the radical unit and the adjacent phenyl ring of only about $6^{\circ} .{ }^{30}$ The overall tolane backbone is fairly planar. The $\mathrm{N}(2)-\mathrm{O}(1)$ 1.271(1) A bond distances are similar for this type of compound.

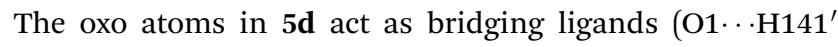

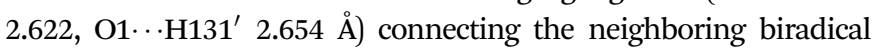
molecules into 1D zig-zag shaped chain structures in the crystal cell. These radical ribbons are then piled up along the $b$ crystallographic axis (Fig. S5, ESI $\dagger$ ), using $\mathrm{C} 7 \cdots \mathrm{C} 10^{\prime} 3.381 \AA$ close contacts to stabilize the packing (Fig. 6 and Fig. S7, ESI $\dagger$ ).

\section{Magnetic characterization}

To gain a more complete picture of the influence of a given $\pi$-spacer on the electronic properties, and especially on the intra- and inter-dimer exchange couplings, DFT calculations were performed. To get a first idea on the sizeable changes of the exchange interaction in the studied biradical models, geometry optimization with the B3LYP hybrid function and the $6-31 \mathrm{G}^{*}$ basis set was carried out. ${ }^{31}$ Then the broken symmetry approach (BS) for the singlet and triplet states with the BLYP functional (to avoid Hartree-Fock contamination) and the same basis set were applied. ${ }^{12}$ Therefore, the direct exchange interaction for a weakly coupled spin dimer can be described as $J / k_{\mathrm{B}}=E(\mathrm{BS})-E(T)$, since the spin expectation 
Table 2 Calculated $J_{\text {intra }}^{\text {calc }}$ and experimentally obtained $J_{\text {intra }}^{\text {exp intra-dimer }}$ exchange coupling constants. $z J_{\text {inter }}^{\prime}$ calc describes the inter-dimer coupling, where $z$ is the number of the nearest neighbors. $T_{\max }$ corresponds to the maximum in the $\chi_{\text {mol }}(T)$ plot

\begin{tabular}{|c|c|c|c|c|c|}
\hline Biradical & $T_{\max }[\mathrm{K}]$ & $J_{\text {intra }}^{\text {calc } a}[\mathrm{~K}]$ & $J_{\text {intra }}^{\text {calc } b}[\mathrm{~K}]$ & $J_{\text {intra }}^{\exp }[K]$ & $z J_{\text {inter }}^{\prime \exp }[\mathrm{K}]$ \\
\hline 1c & 6.8 & -19.6 & -9.8 & $-5.4 \pm 0.2$ & $-1.4 \pm 0.4$ \\
\hline $2 c$ & 53 & -2.4 & -3.1 & $-12.0 \pm 3.0^{c}$ & $-42.4 \pm 1.7^{c}$ \\
\hline 1d & - & -2.4 & -1.1 & $<-1.5$ & - \\
\hline 3d & 4.2 & -4.7 & -5.0 & $-3.3 \pm 0.1$ & $-2.0 \pm 0.5$ \\
\hline $4 d$ & 3.2 & -3.2 & -3.6 & $-2.5 \pm 0.1$ & $-5.8 \pm 1.4$ \\
\hline $5 d$ & 2.8 & -2.6 & -1.6 & $-2.2 \pm 0.1$ & $-0.5 \pm 0.1$ \\
\hline
\end{tabular}

${ }^{a}$ Optimized geometries were obtained from DFT calculations (B3LYP, 6-31G*), then single point calculations for the energy of the broken symmetry and the triplet state were applied (UBLYP, $6-31 \mathrm{G}^{*}$ for the evaluation of $J) .{ }^{31 b}$ The exchange interactions were evaluated for X-ray crystal structures applying the broken symmetry approach with the BLYP functional and the $6-31 \mathrm{G}^{*}$ basis set. ${ }^{c}$ Note that dominant magnetic exchange in $2 \mathrm{c}$ is between two adjacent $\mathrm{NN}$ units belonging to different biradicals (for details see the text and Fig. 3).

values $\left\langle S^{2}(\mathrm{BS})\right\rangle$ and $\left\langle S^{2}(T)\right\rangle$ for the broken symmetry configuration are close to 1 and for the triplet configuration they are close to 2 such that their difference is close to unity. ${ }^{32}$ Notably, in the case of antiferromagnetic interactions $J$ takes negative values. The calculations were then redone in accordance with the X-ray geometries, as listed in Table 2.

Applying a Quantum Design SQUID magnetometer the temperature dependence of the molar magnetic susceptibilities $\chi_{\text {mol }}(T)$ of microcrystalline samples $1 \mathbf{c}, 2 \mathbf{2 c}, 1 \mathbf{1 d}, \mathbf{3 d}, \mathbf{4 d}$, and $5 \mathbf{d}$ was determined in the range of $2 \mathrm{~K} \leq T \leq 270 \mathrm{~K}$ in a magnetic field $B=1 \mathrm{~T}$. The obtained data were corrected for the temperature-independent diamagnetic core contribution of the constituents. ${ }^{33}$ The magnetic contribution of the sample holder was determined in an independent experiment without a sample. The results are graphically displayed in the form of $\chi_{\mathrm{mol}} T v s . T$ in the main panel, and $\chi_{\mathrm{mol}} v s . T$ in the insets of Fig. 7 and 8 and in the $\operatorname{ESI}_{\dagger} \dagger$ (Fig. S8). AC-susceptibility measurements $\left(\chi_{\mathrm{ac}}\right)$ were performed only on $\mathbf{5 d}$ as a function of the magnetic field at $T=0.028 \mathrm{~K}$ using an ultra-high resolution AC-susceptometer adapted to a ${ }^{3} \mathrm{He}-{ }^{4} \mathrm{He}$ top-loading dilution refrigerator. The compensated-coil susceptometer was optimized for measuring small single crystals in the $\mathrm{mg}$ range.

Generally, all the biradicals under investigation (1c, 2c, 1d, 3d, 4d, 5d) featured a similar magnetic behavior in the studied temperature range. The observed $\chi_{\mathrm{mol}} T$ values at $300 \mathrm{~K}$ of the nitroxides are around $0.7 \mathrm{~cm}^{3} \mathrm{~K} \mathrm{~mol}^{-1}$. Importantly, experimental data are rather close to the theoretical value of $0.75 \mathrm{~cm}^{3} \mathrm{~K} \mathrm{~mol}^{-1}$, which is expected for the two uncoupled spin $S=1 / 2$ units (indicated by the broken line in Fig. 7). This indicates the high quality of the studied single crystals.

As a typical example, $\chi_{\mathrm{mol}} T(T)$ of NN-biradical $1 \mathrm{c}$ is shown in Fig. 7. Upon decreasing the temperature $\chi_{\text {mol }} T$ features an approximately linear moderate decrease down to $\sim 120 \mathrm{~K}$ followed by a more pronounced drop below $\sim 50 \mathrm{~K}$. This overall behavior reflects the dominant antiferromagnetic intra-dimer coupling $J_{\text {intra }}$. The inset of Fig. 7 shows the molar magnetic susceptibility as a function of temperature. The Bleany-Bowers equation ${ }^{34}$ for a model of an isolated dimer $\chi_{\text {iso }}$ with a mean-field correction was

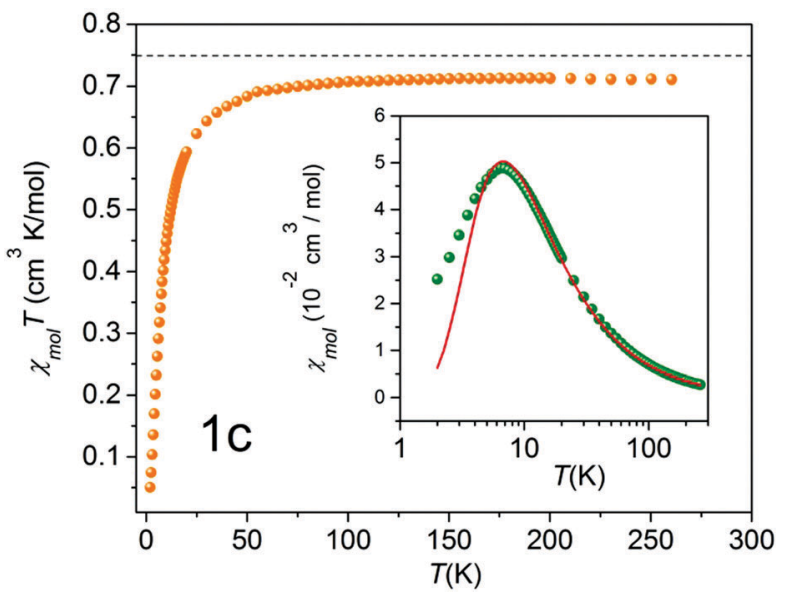

Fig. $7 \chi_{\mathrm{mol}} T$ as a function of temperature (solid orange circles) of $1 \mathrm{c}$. The black broken line indicates the theoretical value of $0.75 \mathrm{~cm}^{3} \mathrm{~K} \mathrm{~mol}^{-1}$, expected for the two uncoupled spin $S=1 / 2$ entities. Inset: Molar susceptibility $\chi_{\mathrm{mol}}$ as a function of temperature (solid green circles) in a semilog representation, and a theoretical fit with a mean-field correction (red solid line). ${ }^{33}$

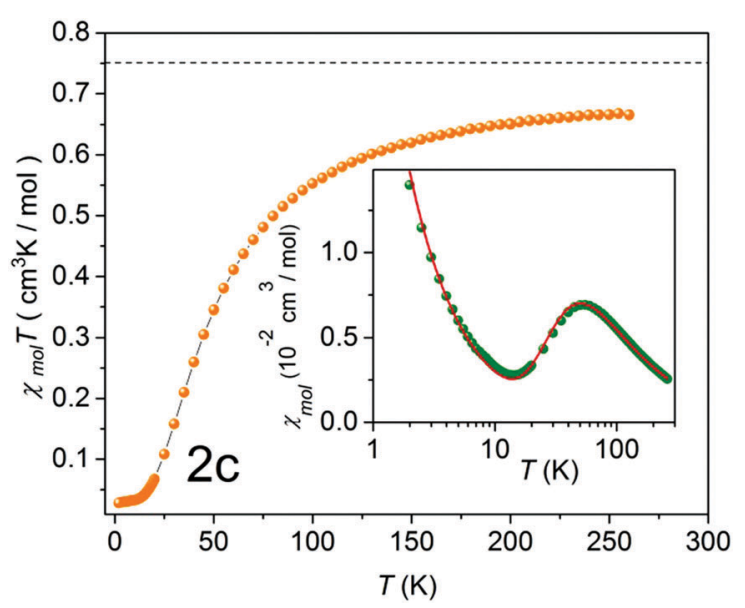

Fig. $8 \chi_{\mathrm{mol}} T$ as a function of temperature (solid orange circles) of $\mathbf{2 c}$. The black broken line indicates the theoretical value of $0.75 \mathrm{~cm}^{3} \mathrm{~K} \mathrm{~mol}^{-1}$, expected for the two uncoupled spin $S=1 / 2$ entities. Inset: Molar susceptibility $\chi_{\mathrm{mol}}$ as a function of temperature (solid green circles), and a theoretical fit with a mean-field correction (red solid line), ${ }^{33}$ including a Curie term corresponding to $S=1 / 2$ entities.

applied to fit the experimental data (solid line in the inset of Fig. 7). Using this fitting the sizes of the intra-dimer $J_{\text {intra }}$ and inter-dimer $z J_{\text {inter }}^{\prime}$ (where $z$ is the number of the nearest neighbors) coupling constants were extracted:

$$
\chi_{\mathrm{mol}}=\chi_{\text {iso }} /\left[1-\left(z J^{\prime} \cdot \chi_{\text {iso }} / N g^{2} \mu_{\mathrm{B}}^{2}\right)\right]
$$

Thus, for 1c an experimental intra-dimer coupling constant $J_{\text {intra }} / k_{\mathrm{B}}=-5.4 \pm 0.2 \mathrm{~K}$ was obtained. This value is in tangible agreement with the coupling constant acquired from the broken-symmetry approach (Table 2). It should be mentioned that the experimental and theoretical $J_{\text {intra }}$ values of $1 \mathrm{c}$ are very similar to the ones reported for tolane $\mathrm{NN}\left(J_{\text {intra }} / k_{\mathrm{B}}=-4.8 \mathrm{~K}\right) .{ }^{11}$ 
In light of this it is reasonable to assume that a mere substitution of $\mathrm{N}$ for $\mathrm{C}$ in position $X$ (as indicated in Fig. 1), if it does not severely affect the geometry of a given crystal structure, has no practical influence on the magnetic interactions.

An unexpected result was acquired for NN derivative 2c where $\mathrm{N}$ was substituted with $\mathrm{C}$ in the $\mathrm{Y}$ position (Fig. 1). For this system the DFT calculations predict $J_{\text {intra }}$ values of a few Kelvin, i.e. similar to those found for the other materials under investigation. The magnetic properties of 2c determined experimentally are shown in Fig. 8 . The $\chi_{\mathrm{mol}} T$ data decreased gradually and leveled off around $20 \mathrm{~K}$ at a small value of approximately $0.02 \mathrm{~cm}^{3} \mathrm{~K} \mathrm{~mol}^{-1}$. In the inset of Fig. 8 a broad maximum in $\chi_{\mathrm{mol}}$ at $53 \mathrm{~K}$ is clearly visible. From a theoretical fit $^{33}$ corrected with a Curie term for uncoupled $S=1 / 2$ entities (solid red line in the inset of Fig. 8), an inter-dimer coupling constant of $J_{\text {inter }} / k_{\mathrm{B}}=-42.4 \mathrm{~K}$ was obtained. This is significantly larger than $J_{\text {intra }}$ of $\mathbf{1 c}$ and tolane NN in ref. 11.

This observation is conceivable in terms of the crystal structure peculiarities. As described above, the radical units in nitronyl nitroxide $2 \mathrm{c}$ are far more twisted $\left(\sim 53^{\circ}\right)$ in comparison to other biradical models described here. The further analysis of the X-ray data revealed exceptionally short contacts of $\sim 3.51 \AA$ between two neighboring NO fragments in 3,3'-diazatolane nitronyl nitroxide 2c (Fig. S7, ESI $\dagger$ ). Apparently, these short contacts are responsible for the unpredicted strong antiferromagnetic exchange interactions found in the solid. Taking only these intermolecular interactions into account and replacing the second radical unit by hydrogen, the value $J_{\text {inter }} / k_{\mathrm{B}}=$ $-45.6 \mathrm{~K}$ was calculated, which was very close to the experimentally obtained value of $-42.4 \pm 1.7 \mathrm{~K}$ (Table 2 ). Such short inter-dimer distances between spin centers could not be found in the other biradicals.

In accordance with the theoretical predictions and crystal structure analysis IN biradicals 1d, 3d, 4d and 5d featured weak antiferromagnetic intramolecular coupling. Their intra-dimer exchange constants are listed in Table 2 (see also Fig. S8, ESI $\dagger$ ). Interestingly, in the case of IN-biradicals 3d and $\mathbf{4 d}$ the $\mathrm{N}$-heteroatomic substitution has barely affected their magnetic properties in accordance to the previous statement. From the experimental data recorded for imino biradical 1d no clear maximum could be resolved, indicating an extremely weak intra-dimer coupling constant $<-1.5 \mathrm{~K}$.

Remarkably, a closer examination of the low-temperature $\left(T<J_{\text {intra }} / k_{\mathrm{B}}\right)$ susceptibility data for IN-biradical $\mathbf{5 d}$ revealed a significant deviation from the isolated-dimer model. Typically, magnetization of the isolated-dimer systems changes in a step-wise manner at the saturation field $B_{\mathrm{s}}$ and temperatures $T<J_{\text {intra }} / k_{\mathrm{B}}$. Such field-temperature induced transitions correspond to the alteration in the spin-state population of the dimers, namely, the occupation of the low-lying triplet state. This phenomenon is reflected in the form of a single peak in susceptibility $\chi$, the field derivative of magnetization. Fig. 9 shows the AC-susceptibility of IN biradical 5d as a function of the magnetic field at $0.028 \mathrm{~K}$ (right scale) together with the magnetization of the material at the same temperature (left scale).

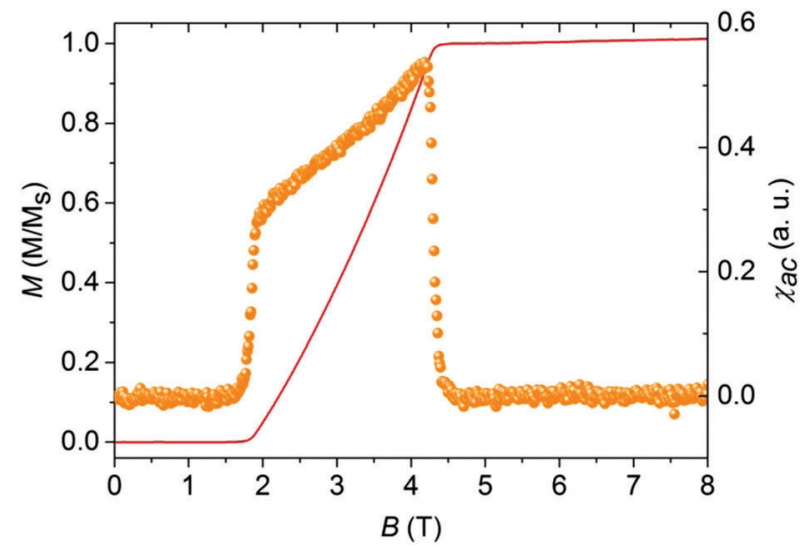

Fig. 9 Magnetization $M(B)$ of $\mathbf{5 d}$ (solid red line, left scale) at $28 \mathrm{mK}$ normalized to the saturation magnetization together with the magnetic AC-susceptibility $\chi_{a c}(B)$ (orange full circles, right scale)

The AC susceptibility was measured only for IN biradical 5d since only for this sample a large single crystal was available. Polycrystalline samples have been shown to be critical for their intercrystalline contacts and depend on their powder to crystallinity content and several $\mathrm{mg}$ are still needed. The data highlight a well-pronounced double-peak feature in $\chi_{\mathrm{ac}}$, an evidence of a field-induced ordered state between $B_{\mathrm{c} 1}=1.8 \mathrm{~T}$ and $B_{\mathrm{c} 2}=4.3 \mathrm{~T}$ at $0.028 \mathrm{~K}$. Such field-induced phases are expected for a coupled-dimer system where the lower edge of a band of magnetic excitations crosses the ground state at $B_{\mathrm{c} 1}$. Here, $B_{\mathrm{c} 2}$ corresponds to the saturation field $B_{\mathrm{s}}$ where the full magnetization of the system is obtained. The magnetization exhibits no hysteretic behavior. This feature is attributed to small magnetic intermolecular interactions between the neighboring biradical molecules mediated via hydrogen bonds. The strength of these interactions depends on the distance and the relative orientation of the radicals. ${ }^{35,36}$ The anomalies at the critical fields $B_{\mathrm{c} 1}$ and $B_{\mathrm{c} 2}$ are much sharper than the one found in a quasi-2D system. ${ }^{11}$ More likely, the inter-dimer coupling in 5d has a 3D character, and therefore, this field-induced ordered phase can be described in terms of a BEC of triplons.

\section{Experimental section}

\section{Materials and methods}

All chemicals and reagents were used as received from commercial sources (Acros Organics, Aldrich, Fluka, Lancaster, Merck and Strem) without additional purification. Solvents for synthesis were used as received, unless otherwise mentioned. ESR spectra were recorded in dilute, oxygen-free solutions in toluene, concentrations $\sim 10^{-4} \mathrm{~mol} \mathrm{~L}^{-1}$, using a Bruker ESP300 E X-band spectrometer equipped with an NMR gaussmeter (Bruker ER035), a frequency counter (Bruker ER041XK) and a variable temperature control continuous flow $\mathrm{N}_{2}$ cryostat (Bruker B-VT 2000). The $g$-factor corrections were obtained using DPPH $(g=2.0037)$ as the standard. UV-Vis spectra were recorded in toluene solutions with a PerkinElmer spectrometer (UV/Vis/NIR Lambda 900) using a $1 \mathrm{~cm}$ optical path quartz cell at room temperature, 
unless otherwise specified. ${ }^{1} \mathrm{H}$ and ${ }^{13} \mathrm{C}$ NMR spectra were recorded on a Bruker DPX 250, Bruker DMX 300 spectrometer. Solid powders were pressed and IR spectra of the samples were recorded as they were (Nicolet 730 FT-IR spectrometer). Mass spectra (FDMS) were obtained on a VG Instruments ZAB-2 mass spectrometer. Elemental analyses were performed at the University of Mainz, Faculty of Chemistry and Pharmacy on a Foss Heraeus Varieo EL. The melting points were measured on a Büchi B-545 apparatus (uncorrected) by using open-ended capillaries. Crystallographic data for the reported structures of the biradicals have been deposited at the Cambridge Crystallographic Data Centre. 2,3-Bis(hydroxyamino)-2,3-dimethylbutane (BHA) synthesis was described elsewhere. ${ }^{11,15}$

A1. General procedure for Sonogashira-Hagihara coupling reaction. An aryl bromide ( $21.7 \mathrm{mmol}, 1$ eq.) was transferred into a flame-dried flask in an argon stream. A mixture of dry $\mathrm{DMF}_{\mathrm{NEt}}$ (50 mL, $1: 1$ ) solvents was added through the rubber septum. The solution was carefully deaerated by purging with argon for 20-25 $\mathrm{min}$, and a catalytic mixture of $\mathrm{Pd}\left(\mathrm{PPh}_{3}\right)_{2} \mathrm{Cl}_{2}$ (1.1 mmol, 0.05 eq.), $\mathrm{PPh}_{3}(2.2 \mathrm{mmol}, 0.1$ eq.), and CuI (1.1 mmol, 0.05 eq.) was added at once. The resulting mixture was slightly heated (to $45{ }^{\circ} \mathrm{C}$ ) and ethynyltrimethylsilane (32.6 mmol, 1.5 eq.) was added through the septum. After that the heating was increased to $80{ }^{\circ} \mathrm{C}$. A white precipitate began to form after $\sim 15 \mathrm{~min}$ of heating. After the reported time ( 4 to $16 \mathrm{~h}$ ), the mixture was cooled to ambient temperature, and the crystalline white solid of triethylamine hydrobromide was isolated by filtration. The orange-brown filtrate was concentrated, mixed with $\mathrm{NH}_{4} \mathrm{Cl}$ saturated aqueous solution $(50 \mathrm{~mL})$, and extracted with dichloromethane or diethyl ether $(3 \times 40 \mathrm{~mL})$. The organic fractions were combined, dried over magnesium sulfate, and concentrated with silica gel in vacuo. The residue was purified using column chromatography.

A2. Using the same set-up and the catalyst/reagent ratio a mixture of dry $\mathrm{NEt}_{3} / \mathrm{CH}_{3} \mathrm{CN}(1: 1)$ as the solvent media was preferred. Here, after 5 minutes of stirring at room temperature formation of triethylamine hydrobromide salt was observed. The light yellow reaction mixture was stirred at room temperature for 17-19 h. The work-up was done in accordance with protocol A1.

2-Bromo-5-pyridinecarbaldehyde (7). 2,5-Dibromopyridine 6 (10 g, $42.2 \mathrm{mmol}$ ) was charged into a flame-dried flask, evacuated and kept under argon. Dry diethylether $(250 \mathrm{~mL})$ was added, and the resulting solution was cooled to $-78{ }^{\circ} \mathrm{C}$ in a dry ice/acetone bath. Then $n$-BuLi (34 mL, 1.6 M in hexane, $53.8 \mathrm{mmol}$ ) was added dropwise within 20-25 min. Upon addition of $n$-BuLi the resulting solution turned red. The temperature $\left(-78{ }^{\circ} \mathrm{C}\right)$ was kept constant for further $45 \mathrm{~min}$, and then dry dimethylformamide $\left(4.7 \mathrm{~mL}, d=0.94 \mathrm{~g} \mathrm{~mL}^{-1}, 60.3 \mathrm{mmol}\right.$ ) was added dropwise within $15 \mathrm{~min}$. The mixture turned deep red. The temperature $\left(-78^{\circ} \mathrm{C}\right)$ was maintained for further $90 \mathrm{~min}$, and then slowly increased. After that $3 \% \mathrm{HCl}(100 \mathrm{~mL})$ was added. The resulting mixture was

¥ Crystallographic data for the reported structures of biradicals 1c, 2c, 1d, 3d, 4d and $\mathbf{5 d}$ have been deposited with the Cambridge Crystallographic Data Centre as supplementary publication no. CCDC 823716, 816632, 816630, 823717, 858078, 810139, respectively. stirred for $20 \mathrm{~min}$. Diethylether was concentrated in vacuo. To the oily residue $60 \mathrm{~mL}$ of dichloromethane was added, and the mixture was neutralized with solid $\mathrm{NaHCO}_{3}$. The organic phase was separated and the water layer was extracted with dichloromethane $(3 \times 60 \mathrm{~mL})$. Combined organic extracts were dried over $\mathrm{MgSO}_{4}$, and the solvent was evaporated. Crystals were filtered and washed carefully with hexane $(3 \times 20 \mathrm{~mL})$. The filtrate was reduced to a small volume (ca. $2 \mathrm{~mL}$ ), and purified on a flash column ( $\mathrm{SiO}_{2}$, dichloromethane). Aldehyde 7 was obtained in $72 \%$ total yield. ${ }^{1} \mathrm{H}-\mathrm{NMR}\left(\mathrm{CDCl}_{3}, 250 \mathrm{MHz}, 298 \mathrm{~K}\right.$, 16 scan), $\delta$ ppm: 7.66 (d, $\left.1 \mathrm{H},{ }^{3} J=8 \mathrm{~Hz}, \mathrm{H}-3\right), 8.01$ (dd, $1 \mathrm{H},{ }^{3} J=8$ $\mathrm{Hz}, \mathrm{H}-4), 8.82$ (s, 1H, H-6), 10.08 (s, 1H, -CHO). ${ }^{13} \mathrm{C}-\mathrm{NMR}$ $\left(\mathrm{CDCl}_{3}, 63 \mathrm{MHz}, 298 \mathrm{~K}, 256 \mathrm{scan}\right) \delta \mathrm{ppm}: 129.4$ (C-3), 131 (C-5), 137.9 (C-4), 148.7 (C-2), 152.9 (C-6), 189.9 (-CHO). MS-FD $\left(70 \mathrm{eV}, \mathrm{CH}_{2} \mathrm{Cl}_{2}\right) \mathrm{m} / \mathrm{z}$ : $187.3\left(\mathrm{M}^{+}\right)$, MW calculated $\mathrm{C}_{6} \mathrm{H}_{4} \mathrm{BrNO}$ $\left(\mathrm{MW}^{+}\right)$186.01.

2-Bromo-5-[1,3]-dioxolan-2-yl-pyridine (8). Starting compound 7 ( $5 \mathrm{~g}, 26.85 \mathrm{mmol}$ ) was charged into a flask together with benzene $(100 \mathrm{~mL})$, ethyleneglycol $(2.7 \mathrm{~mL}, 48.5 \mathrm{mmol})$ and a catalytic amount of para-toluene-sulfonic acid $(0.4 \mathrm{~g}, 2.1 \mathrm{mmol})$. The solution was heated to reflux with Deane-Stark for $20 \mathrm{~h}$. Then the reaction mixture was cooled down to rt, and neutralized with $\mathrm{NaHCO}_{3}$ aqueous solution, and the phases were separated. The aqueous layer was extracted with small portions of benzene $(3 \times 15 \mathrm{~mL})$. Benzene extracts were collected, dried over $\mathrm{MgSO}_{4}$ and filtered. The solvent was evaporated under reduced pressure. Compound 8 was obtained as a yellowish oil in $85 \%$ yield $(5.4 \mathrm{~g}$ ), and was used further without additional purification. ${ }^{1} \mathrm{H}-\mathrm{NMR}$ $\left(\mathrm{CDCl}_{3}, 250 \mathrm{MHz}, 298 \mathrm{~K}, 16 \mathrm{scan}\right), \delta \mathrm{ppm}: 3.92\left(\mathrm{~m}, 4 \mathrm{H},-\mathrm{CH}_{2}\right), 5.71$ (s, 1H, H-7), 7.34 (d, $\left.1 \mathrm{H},{ }^{3} J=8 \mathrm{~Hz}, \mathrm{H}-3\right), 7.62$ (dd, $1 \mathrm{H},{ }^{3} J=8 \mathrm{~Hz}$, $\mathrm{H}-4), 8.47$ (s, 1H, H-6). ${ }^{13} \mathrm{C}-\mathrm{NMR}\left(\mathrm{CDCl}_{3}, 63 \mathrm{MHz}, 298 \mathrm{~K}, 256 \mathrm{scan}\right)$, $\delta$ ppm: $64.4\left(-\mathrm{CH}_{2}\right), 100.2$ (C-7), 126.9 (C-3), 132.4 (C-5), 135.9 (C-4), 142 (C-2), 147.9 (C-6). MS-FD (70 eV, $\mathrm{CH}_{2} \mathrm{Cl}_{2}$ ) m/z: $231.2\left(\mathrm{M}^{+}\right)$, MW calculated $\mathrm{C}_{8} \mathrm{H}_{8} \mathrm{BrNO}_{2}\left(\mathrm{MW}^{+}\right) 230.06$.

2-Ethynyl-trimethyl-silyl-5-[1,3]-dioxolan-2-yl-pyridine Derivative 9 was synthesized according to the synthetic procedure A1. Purification on a silica gel column with dichloromethane/ hexane as the eluent $(3: 2)$ afforded precursor 9 in $89 \%$ yield. ${ }^{1} \mathrm{H}-\mathrm{NMR}\left(\mathrm{CDCl}_{3}, 250 \mathrm{MHz}, 298 \mathrm{~K}, 16 \mathrm{scan}\right), \delta \mathrm{ppm}: 0.28(\mathrm{~s}, 9 \mathrm{H}$, $\left.-\mathrm{CH}_{3}\right), 4.09\left(\mathrm{~m}, 4 \mathrm{H},-\mathrm{CH}_{2}\right), 5.85(\mathrm{~s}, 1 \mathrm{H}, \mathrm{H}-7), 7.47\left(\mathrm{~d}, 1 \mathrm{H},{ }^{3} J=\right.$ $8 \mathrm{~Hz}, \mathrm{H}-3), 7.74$ (dd, $\left.1 \mathrm{H},{ }^{3} J=8 \mathrm{~Hz}, \mathrm{H}-4\right), 8.65$ (s, 1H, H-6). ${ }^{13} \mathrm{C}-\mathrm{NMR}\left(\mathrm{CDCl}_{3}, 63 \mathrm{MHz}, 298 \mathrm{~K}, 256 \mathrm{scan}\right), \delta \mathrm{ppm}: 0\left(-\mathrm{CH}_{3}\right)$, $67.1\left(-\mathrm{CH}_{2}\right), 94.8$ (C-9), 102.2 (C-7), 104.1 (C-8), 126.7 (C-3), 132.6 (C-5), 134.9 (C-4), 143.4 (C-2), 148.6 (C-6). MS-FD (70 eV, $\left.\mathrm{CH}_{2} \mathrm{Cl}_{2}\right) \mathrm{m} / z: 247.1\left(\mathrm{M}^{+}\right)$, MW calculated $\mathrm{C}_{13} \mathrm{H}_{17} \mathrm{NO}_{2} \mathrm{Si}\left(\mathrm{MW}^{+}\right)$ 247.37.

2-Ethynyl-5-[1,3]-dioxolan-2-yl-pyridine (10). A solution of 2-ethynyl-trimethyl-silyl-5-[1,3]-dioxolan-2-yl-pyridine 10 (0.33 g, $1.3 \mathrm{mmol})$ in THF $(25 \mathrm{~mL})$ was treated with $1 \mathrm{~N} \mathrm{NaOH}(50 \mathrm{~mL})$ under argon at $5{ }^{\circ} \mathrm{C}$ (ice/water bath). After $35 \mathrm{~min}$ the reaction was complete (according to the TLC analysis of the reaction mixture aliquots). The solvent was evaporated under reduced pressure, and brine $(50 \mathrm{~mL})$ was added to the residue. The aqueous layer was extracted with dichloromethane $(3 \times 60 \mathrm{~mL})$. The combined organic fractions were dried over $\mathrm{MgSO}_{4}$ and concentrated in vacuo. The so-obtained compound $\mathbf{1 0}$ (89\% yield) 
was used for the next step without additional purification. ${ }^{1} \mathrm{H}-\mathrm{NMR}\left(\mathrm{CDCl}_{3}, 250 \mathrm{MHz}, 298 \mathrm{~K}, 16 \mathrm{scan}\right), \delta \mathrm{ppm}: 3.2(\mathrm{~s}, 1 \mathrm{H}$, $\mathrm{H}-9), 4.11\left(\mathrm{~m}, 4 \mathrm{H},-\mathrm{CH}_{2}\right), 5.88$ (s, $\left.1 \mathrm{H}, \mathrm{H}-7\right), 7.51$ (d, $1 \mathrm{H},{ }^{3} \mathrm{~J}=8 \mathrm{~Hz}$, $\mathrm{H}-3$ ), 7.78 (dd, $\left.1 \mathrm{H},{ }^{3} \mathrm{~J}=8 \mathrm{~Hz}, \mathrm{H}-4\right), 8.69$ (s, 1H, H-6). ${ }^{13} \mathrm{C}-\mathrm{NMR}$ $\left(\mathrm{CDCl}_{3}, 63 \mathrm{MHz}, 298 \mathrm{~K}, 256 \mathrm{scan}\right), \delta$ ppm: $65.4\left(-\mathrm{CH}_{2}\right), 72.8(\mathrm{C}-9)$, 81.4 (C-8), 101.8 (C-7), 127.4 (C-3), 134.2 (C-5), 134.7 (C-4), 142.5 (C-2), 149.4 (C-6). MS-FD (70 eV, $\left.\mathrm{CH}_{2} \mathrm{Cl}_{2}\right) \mathrm{m} / z: 175.3\left(\mathrm{M}^{+}\right), \mathrm{MW}$ calculated $\mathrm{C}_{10} \mathrm{H}_{9} \mathrm{NO}_{2}\left(\mathrm{MW}^{+}\right)$175.18.

2,2'-Ethyne-1,2-diylbis(pyridine-5-carbaldehyde) (1a). Sonogashira cross-coupling between precursors $\mathbf{8}$ and $\mathbf{1 0}$ was realized following methodology A2. As the major product 1,2-bis(5-(1,3-dioxolan-2yl)pyridine-2-yl)ethyne was isolated in $72 \%$ yield using flash chromatography ( $\mathrm{SiO}_{2}$, dichloromethane). ${ }^{1} \mathrm{H}-\mathrm{NMR}\left(\mathrm{CDCl}_{3}\right.$, $250 \mathrm{MHz}, 298 \mathrm{~K}, 16 \mathrm{scan}), \delta \mathrm{ppm}: 4.01$ (m, 8H, $-\mathrm{CH}_{2}$ ), 5.8 (s, $2 \mathrm{H}, \mathrm{H}-7), 7.56$ (d, $\left.2 \mathrm{H},{ }^{3} \mathrm{~J}=8 \mathrm{~Hz}, \mathrm{H}-3\right), 7.72\left(\mathrm{dd}, 2 \mathrm{H},{ }^{3} \mathrm{~J}=8 \mathrm{~Hz}, \mathrm{H}-4\right)$, 8.65 (s, 2H, H-6). ${ }^{13} \mathrm{C}-\mathrm{NMR}\left(\mathrm{CDCl}_{3}, 63 \mathrm{MHz}, 298 \mathrm{~K}, 256 \mathrm{scan}\right)$, $\delta$ ppm: $65.8\left(-\mathrm{CH}_{2}\right), 88.5(\mathrm{C}-8), 101.9(\mathrm{C}-7), 127.8(\mathrm{C}-3), 133.9$ (C-5), 134.9 (C-4), 143.5 (C-2), 149.1 (C-6). MS-FD (70 eV, $\mathrm{CH}_{2} \mathrm{Cl}_{2}$ ) $m / z: 324.5\left(\mathrm{M}^{+}\right)$, MW calculated $\mathrm{C}_{18} \mathrm{H}_{16} \mathrm{~N}_{2} \mathrm{O}_{4}\left(\mathrm{MW}^{+}\right) 324.33$.

Next, to the solution of the corresponding dioxolane precursor $(0.38 \mathrm{~g}, 1.35 \mathrm{mmol})$ in an acetone-water mixture $(7: 1$, $40 \mathrm{~mL}$ ) para-toluene-sulfonic acid ( $52 \mathrm{mg}, 0.027 \mathrm{mmol}, 2 \mathrm{~mol} \%$ ) was added. The progress of the reaction was monitored by TLC $\left(\mathrm{SiO}_{2}\right.$, hexane/ethyl acetate, $\left.3: 1\right)$. After $84 \mathrm{~h}$ of stirring at room temperature the reaction was complete. Acetone was evaporated, and the residue was diluted with dichloromethane $(30 \mathrm{~mL})$. The organic layer was separated, and the water phase was extracted with dichloromethane $(3 \times 30 \mathrm{~mL})$. The combined organic extracts were dried over $\mathrm{MgSO}_{4}$. The solvent was removed in vacuo giving $0.26 \mathrm{~g}(81 \%)$ of dialdehyde $1 \mathrm{a}$ as a yellow solid. ${ }^{1} \mathrm{H}-\mathrm{NMR}\left(\left(\mathrm{CD}_{3}\right)_{2} \mathrm{SO}, 250 \mathrm{MHz}, 298 \mathrm{~K}, 16 \mathrm{scan}\right), \delta \mathrm{ppm}: 8.01(\mathrm{~d}, 2 \mathrm{H}$, $\left.{ }^{3} J=8 \mathrm{~Hz}, \mathrm{H}-2\right), 8.37$ (dd, $\left.2 \mathrm{H},{ }^{3} J=8 \mathrm{~Hz}, \mathrm{H}-3\right), 9.19$ (s, 2H, H-6), 10.20 (s, 2H, -CHO). ${ }^{13} \mathrm{C}-\mathrm{NMR}\left(\left(\mathrm{CD}_{3}\right)_{2} \mathrm{SO}, 63 \mathrm{MHz}, 298 \mathrm{~K}, 256\right.$ scan), $\delta$ ppm: 90.1 (C-8), 128.8 (C-3), 131.1 (C-5), 137.3 (C-4), 145.7 (C-2), 152.2 (C-6), 192.2 (-CHO). MS-FD (70 eV, $\mathrm{CH}_{2} \mathrm{Cl}_{2}$ ) m/z: 236.3 $\left(\mathrm{M}^{+}\right)$, MW calculated $\mathrm{C}_{14} \mathrm{H}_{8} \mathrm{~N}_{2} \mathrm{O}_{2}\left(\mathrm{MW}^{+}\right)$236.23.

5-Bromo-2-pyridinecarbaldehyde (11). $n$-BuLi (48 mL, $1.6 \mathrm{M}$ solution in hexane, $76.8 \mathrm{mmol}$ ) and $50 \mathrm{~mL}$ of dry toluene were transferred to a flame-dried flask filled with argon through the rubber septum. The solution was cooled to $-78{ }^{\circ} \mathrm{C}$ in a dry ice/acetone bath, and a solution of 2,5-dibromopyridine 6 (15 g, $63 \mathrm{mmol})$ in dry toluene $(300 \mathrm{~mL})$ was added dropwise within $1.5 \mathrm{~h}$. Upon addition of the starting compound 6 to the mixture the color changed from colorless to yellow. The mixture was stirred at $-78{ }^{\circ} \mathrm{C}$ for $30 \mathrm{~min}$, and the temperature was allowed slowly to increase until $-65{ }^{\circ} \mathrm{C}$. Then the solution was cooled again to $-78{ }^{\circ} \mathrm{C}$, and dry dimethylformamide $(5.89 \mathrm{~mL}, d=$ $0.94 \mathrm{~g} \mathrm{~mL}^{-1}, 75.8 \mathrm{mmol}$ ) was added slowly dropwise within $20 \mathrm{~min}$. The mixture was allowed to stir overnight, and then decomposed with $3 \% \mathrm{HCl}(100 \mathrm{~mL})$. The organic layer was separated, and the water was extracted with dichloromethane $(4 \times 50 \mathrm{~mL})$. The combined organic extracts were washed with $\mathrm{NaHCO}_{3}$, dried over $\mathrm{MgSO}_{4}$ and the solvents were evaporated in vacuo. The oily residue was purified through a flash column $\left(\mathrm{SiO}_{2}\right.$, petroleum ether/ethyl acetate, $\left.100: 3\right)$. 5-Bromo-2-pyridinecarbaldehyde 11 was synthesized in $49 \%$ yield. ${ }^{1} \mathrm{H}-\mathrm{NMR}\left(\mathrm{CDCl}_{3}\right.$,
$250 \mathrm{MHz}, 298 \mathrm{~K}, 16 \mathrm{scan}$ ), $\delta$ (ppm): 7.8 (d, 1H, H-6), 7.9 (dd, 1H, $\left.{ }^{3} J=8 \mathrm{~Hz}, \mathrm{H}-4\right), 8.78$ (d, 1H, H-3), 9.97 (s, 1H, -C=O). ${ }^{13} \mathrm{C}-\mathrm{NMR}$ $\left(\mathrm{CDCl}_{3}, 63 \mathrm{MHz}, 298 \mathrm{~K}, 256 \mathrm{scan}\right), \delta$ ppm: 122.7 (C-5), 126.2 (C-3), 139.9 (C-4), 151.1 (C-2), 151.5 (C-6), 192.3 (-CHO). MS-FD (70 eV, $\left.\mathrm{CH}_{2} \mathrm{Cl}_{2}\right) \mathrm{m} / \mathrm{z}: 187.3\left(\mathrm{M}^{+}\right)$, MW calculated $\mathrm{C}_{6} \mathrm{H}_{4} \mathrm{BrNO}\left(\mathrm{MW}^{+}\right)$186.01.

5-Ethynyl-trimethyl-silyl-2-formylyl-pyridine (12). Trimethylsilyl derivative 12 was obtained in $87 \%$ yield $(2.37 \mathrm{~g}$ ) following general procedure $\mathrm{A} 1$ after the purification on a silica gel chromatographic column (ethyl acetate/hexane, $3: 100$ ). ${ }^{1} \mathrm{H}-\mathrm{NMR}$ $\left(\mathrm{CDCl}_{3}, 250 \mathrm{MHz}, 298 \mathrm{~K}, 16 \mathrm{scan}\right), \delta \mathrm{ppm}: 0.26\left(\mathrm{~s}, 9 \mathrm{H},-\mathrm{CH}_{3}\right), 7.86$ (d, 2H, $\left.{ }^{3} J=2 \mathrm{~Hz}, \mathrm{H}-3, \mathrm{H}-4\right), 8.77$ (s, 1H, H-4), 8.65 (s, 1H, H-6), 10.02 (s, 1H, $-\mathrm{C}=\mathrm{O}) .{ }^{13} \mathrm{C}-\mathrm{NMR}\left(\mathrm{CDCl}_{3}, 63 \mathrm{MHz}, 298 \mathrm{~K}, 256 \mathrm{scan}\right), \delta \mathrm{ppm}$ : $0\left(-\mathrm{CH}_{3}\right), 98.8$ (C-8), 101.9 (C-7), 121.1 (C-3), 122.4 (C-5), 140.4 (C-4), 150.8 (C-2), 151.7 (C-6), 192.7 (C=O). MS-FD (70 eV, $\left.\mathrm{CH}_{2} \mathrm{Cl}_{2}\right) \mathrm{m} / \mathrm{z}$ : 202.7 $\left(\mathrm{M}^{+}\right)$, MW calculated $\mathrm{C}_{11} \mathrm{H}_{13} \mathrm{NOSi}\left(\mathrm{MW}^{+}\right)$203.31.

5-Ethynyl-2-formyl-pyridine (13). A solution of 12 (1.43 g, $7 \mathrm{mmol})$ and $\mathrm{K}_{2} \mathrm{CO}_{3}(0.46 \mathrm{~g}, 3.33 \mathrm{mmol})$ in a deaerated THF/ water mixture $(80 \mathrm{~mL}, 1: 1 \mathrm{v} / \mathrm{v})$ was stirred at rt for $1.5 \mathrm{~h}$. Brine was added to the mixture, the organic layer was separated, and the water phase was extracted with $\mathrm{Et}_{2} \mathrm{O}(4 \times 30 \mathrm{~mL})$. Combined organic extracts were dried over $\mathrm{Na}_{2} \mathrm{SO}_{4}$, and the solvents were evaporated under reduced pressure. The light-brown solid was washed with a hot hexane/acetone mixture $(\sim 20: 1)$ to give a pale yellow precipitate in $51 \%$ yield $(0.47 \mathrm{~g}) .{ }^{1} \mathrm{H}-\mathrm{NMR}\left(\mathrm{CDCl}_{3}\right.$, $250 \mathrm{MHz}, 298 \mathrm{~K}, 16 \mathrm{scan}$ ), $\delta$ ppm: 3.36 (s, 1H, H-8), 47.87 (d, $\left.2 \mathrm{H},{ }^{3} J=8 \mathrm{~Hz}, \mathrm{H}-3, \mathrm{H}-4\right), 8.79$ (t, $\left.1 \mathrm{H},{ }^{3} J=8 \mathrm{~Hz}, \mathrm{H}-6\right), 10.0$ (s, $1 \mathrm{H}$, $-\mathrm{C}=\mathrm{O}) .{ }^{13} \mathrm{C}-\mathrm{NMR}\left(\mathrm{CDCl}_{3}, 63 \mathrm{MHz}, 298 \mathrm{~K}, 256 \mathrm{scan}\right), \delta \mathrm{ppm}$ : 78.7 (C-7), 83.6 (C-8), 119.9 (C-3), 122.7 (C-5), 139.2 (C-4), 150.4 (C-2), 152.0 (C-6), 191.4 (-CHO). MS-FD (70 eV, $\mathrm{CH}_{2} \mathrm{Cl}_{2}$ ) m/z: 130.3 $\left(\mathrm{M}^{+}\right)$, MW calculated $\mathrm{C}_{8} \mathrm{H}_{5} \mathrm{NO}\left(\mathrm{MW}^{+}\right)$131.13.

5,5'-Ethyne-1,2-diylbis(pyridine-2-carbaldehyde) (2a). Compound 2a was synthesized applying Sonogashira-Hagihara coupling methodology A1 towards precursors 11 and 13. After evaporation of the solvent, the residue was diluted with chloroform $(40 \mathrm{~mL})$, and washed with $\mathrm{NH}_{4} \mathrm{Cl}$ saturated aqueous solution. The solvent was evaporated in vacuo. The product was isolated from the reaction mixture using flash chromatography $\left(\mathrm{SiO}_{2}\right.$, hexane/ chloroform/ethyl acetate, $2: 4: 1$ ), and recrystallized from the hexane/acetone/THF mixture $(2: 1: 1)$ to give 1,2 -(bis(2-formyl-5yl)pyridinyl)ethyne $2 \mathrm{a}$ as a yellow solid in $62 \%$ yield. ${ }^{1} \mathrm{H}-\mathrm{NMR}$ $\left(\mathrm{CDCl}_{3}, 250 \mathrm{MHz}, 298 \mathrm{~K}, 64 \mathrm{scan}\right), \delta \mathrm{ppm}: 8.04$ (d, $2 \mathrm{H},{ }^{3} J=8 \mathrm{~Hz}$, $\mathrm{H}-4$ ), 8.33 (d, 2H, ${ }^{3} \mathrm{~J}=8 \mathrm{~Hz}, \mathrm{H}-3$ ), 9.09 (s, 2H, H-6), 10.03 (s, 2H, -CHO). ${ }^{13} \mathrm{C}-\mathrm{NMR}\left(\mathrm{CDCl}_{3}, 63 \mathrm{MHz}, 298 \mathrm{~K}, 256 \mathrm{scan}\right), \delta$ ppm: 59.3 (C-7), 121.6 (C-4), 125.1 (C-5), 138.8 (C-3), 150.2 (C-2), 150.5 (C-6), 191.2 (-CHO). MS-FD (70 eV, $\left.\mathrm{CH}_{2} \mathrm{Cl}_{2}\right) \mathrm{m} / \mathrm{z}: 236.0\left(\mathrm{M}^{+}\right), \mathrm{MW}$ calculated $\mathrm{C}_{14} \mathrm{H}_{8} \mathrm{~N}_{2} \mathrm{O}_{2}\left(\mathrm{MW}^{+}\right)$236.23.

Biphenyl-4,4'-dicarbaldehyde (3a). $n$-BuLi (10 mL, $1.6 \mathrm{M}$ solution in hexane, $16 \mathrm{mmol}$ ) was charged into a flame-dried flask filled with argon through a septum. Dry TMEDA $(2 \mathrm{~mL}$, $0.013 \mathrm{mmol}$ ) was added. After stirring at room temperature for 15 minutes the mixture was cooled to $-78{ }^{\circ} \mathrm{C}$ (dry ice/i-PrOH), and a solution of 4,4'-dibromo-biphenyl 14 ( $2 \mathrm{~g}, 6.4 \mathrm{mmol})$ in dry THF $(20 \mathrm{~mL})$ was added slowly dropwise within $30 \mathrm{~min}$. The temperature was slightly increased to $-50{ }^{\circ} \mathrm{C}$, due to a dramatic decrease in the solubility of the starting substrate at a lower temperature, and kept at this level for 25 minutes. After that the 
temperature was lowered again to $-78{ }^{\circ} \mathrm{C}$, and dry dimethylformamide $\left(1.25 \mathrm{~mL}, d=0.94 \mathrm{~g} \mathrm{~mL}^{-1}, 16.1 \mathrm{mmol}\right.$ ) was added. The temperature was kept constant for $1 \mathrm{~h}$, and then it was allowed to increase slowly. The obtained dense mixture was decomposed with $\mathrm{NH}_{4} \mathrm{Cl}$ saturated aqueous solution and extracted with diethyl ether $(3 \times 50 \mathrm{~mL})$. The combined organic extracts were dried over $\mathrm{MgSO}_{4}$, and the solvents were evaporated under reduced pressure. The orange residue was recrystallized from dimethylformamide/water $(1: 2)$, yielding $0.78 \mathrm{~g}(58 \%)$ of light-yellow dialdehyde 3a. ${ }^{1} \mathrm{H}$ NMR $\left(\mathrm{CDCl}_{3}, 250.13 \mathrm{MHz}\right), \delta \mathrm{ppm}$ : 7.71-7.75 (d, $\left.4 \mathrm{H},{ }^{3} J=8.0 \mathrm{~Hz}, \mathrm{H}-2\right), 7.92-7.95$ (d, $4 \mathrm{H},{ }^{3} \mathrm{~J}=8.0 \mathrm{~Hz}$, $\mathrm{H}-3$ ), 10.02 (s, 2H, -CHO). ${ }^{13} \mathrm{C}-\mathrm{NMR}\left(\mathrm{CDCl}_{3}, 63 \mathrm{MHz}, 298 \mathrm{~K}, 206\right.$ scan), $\delta$ ppm: 128.1 (C-1), 130.4 (C-2), 136 (C-3), 145.6 (C-4), 191.7 (-CHO). MS-FD (70 eV, $\left.\mathrm{CH}_{2} \mathrm{Cl}_{2}\right) \mathrm{m} / \mathrm{z}: 210.1\left(\mathrm{M}^{+}\right)$, MW calculated $\mathrm{C}_{14} \mathrm{H}_{10} \mathrm{O}_{2}\left(\mathrm{MW}^{+}\right) 210.1$.

Bipyridine-2,2'-dicarbaldehyde (4a). A solution of dimethyl bipyridine 15 ( $1 \mathrm{~g}, 5.38 \mathrm{mmol}, 1$ eq.), NBS (2.49 g, $14 \mathrm{mmol}$, 2.6 eq.), and benzoyl peroxide ( $0.29 \mathrm{~g}, 1.2 \mathrm{mmol}, 0.22$ eq.) in $\mathrm{CCl}_{4}(50 \mathrm{~mL})$ was refluxed under argon for $14 \mathrm{~h}$. The precipitated succinimide was removed from the hot mixture by filtration. The precipitate was washed with $\mathrm{CCl}_{4}(2 \times 10 \mathrm{~mL})$, and the combined $\mathrm{CCl}_{4}$ extracts were evaporated in vacuo. The resulting yellowish solid containing 5,5'-bis(bromomethyl)-2,2'-bipyridine 16 (1 g, $2.95 \mathrm{mmol}, 1$ eq.) was refluxed with hexamethylenetetramine (1.65 g, $11.8 \mathrm{mmol}, 4 \mathrm{eq}$.) in $100 \mathrm{~mL}$ of ethanol/water (1:1) for $60 \mathrm{~h}$. The mixture was extracted with ethyl acetate/toluene $(1: 1)$ $(4 \times 50 \mathrm{~mL})$ to afford effective phase separation. The organic extracts were collected and dried over $\mathrm{MgSO}_{4}$. The filtrate was concentrated in vacuo to a volume of $c a .2 \mathrm{~mL}$, placed on a column with silica, and eluted with an ethyl acetate/hexane gradient solvent mixture $(1: 4,1: 3)$. The colorless fractions were collected and evaporated leading to product $4 \mathrm{a}$ in $57 \%$ overall yield. ${ }^{1} \mathrm{H}$ NMR $\left(\mathrm{CDCl}_{3}, 63 \mathrm{MHz}, 298 \mathrm{~K}, 256 \mathrm{scan}\right), \delta \mathrm{ppm}: 7.60-7.64(\mathrm{~d}, 2 \mathrm{H}$, $\left.{ }^{3} J=8.02 \mathrm{~Hz}, \mathrm{H}-4\right), 7.94-7.98$ (dd, $\left.2 \mathrm{H},{ }^{3} J=8.02 \mathrm{~Hz}, \mathrm{H}-6\right), 8.76$ (d, $\left.2 \mathrm{H},{ }^{3} \mathrm{~J}=1.6 \mathrm{~Hz}, \mathrm{H}-3\right), 10.02$ (s, 2H, -CHO). ${ }^{13} \mathrm{C}-\mathrm{NMR}$ (THF- $d^{8}, 63$ MHz, 298 K, 338 scan), $\delta$ ppm: 121.3 (C-3), 127.6 (C-5), 129.4 (C-4), 131.9 (C-6), 136.4 (C-2), 189.7 (-CHO). MS-FD (70 eV, $\mathrm{CH}_{2} \mathrm{Cl}_{2}$ ) m/z: 211.6 $\left(\mathrm{M}^{+}\right)$, MW calculated $\mathrm{C}_{14} \mathrm{H}_{10} \mathrm{O}_{2}\left(\mathrm{MW}^{+}\right)$212.1.

B1. General synthesis of the 4,4,5,5-tetramethylimidazolidine-1,3-diol precursors 1-5b. A suspension of BHA (1.1 eq. for each aldehyde group) and an aldehyde (1.0 eq.) in toluene ( $5 \mathrm{~mL} / 1 \mathrm{mmol}$ ) was carefully deaerated by purging with argon for $\sim 20-25$ minutes. The flask was provided with a condenser equipped with an argon balloon, and placed in an oil bath. The mixture was heated under argon near reflux for 2-18 h. The progress of the reaction was monitored by TLC $\left(\mathrm{SiO}_{2}\right.$, hexane/ ethyl acetate or dichloromethane with $5 \%$ of methanol). After the process was complete and the flask was cooled down to room temperature, the precipitate (white or yellowish) was filtered off, washed with toluene $(2 \times 10 \mathrm{~mL})$ and heptane $(1 \times 10 \mathrm{~mL})$, and dried in air. The so-obtained derivatives were used further without additional purification.

B2. A solution containing BHA (1.3 eq. for each aldehyde group) and an aldehyde (1.0 eq.) in absolute deaerated methanol $(10 \mathrm{~mL} / 1 \mathrm{mmol})$ was stirred at room temperature for $12-72 \mathrm{~h}$. The formed precipitate was filtered off, washed with cold $\left(\sim 5{ }^{\circ} \mathrm{C}\right)$ methanol and dried in air. The product was used for the next step without additional purification.

2,2' -(2,2' -(Ethyne-1,2-diyl)bis(pyridine-2,5-diyl))bis(4,4,5,5-tetramethylimidazolidine-1,3-diol) (1b). Following protocol B1 starting from dipyridinedialdehyde $1 \mathrm{a}(0.25 \mathrm{~g}, 1.1 \mathrm{mmol})$ was converted into the corresponding imidazolidine derivative $\mathbf{1 b}$ in $4 \mathrm{~h}$. Product 1b was obtained as a pale-yellow powder in $80 \%$ yield $(0.42 \mathrm{~g})$. ${ }^{1} \mathrm{H}-\mathrm{NMR}\left(\left(\mathrm{CD}_{3}\right)_{2} \mathrm{SO}, 250 \mathrm{MHz}, 298 \mathrm{~K}, 128 \mathrm{scan}\right), \delta$ ppm: 1.08 (d, $\left.24 \mathrm{H}, \mathrm{CH}_{3}\right), 4.62$ (s, H-7), $7.72\left(\mathrm{~d}, 2 \mathrm{H},{ }^{3} \mathrm{~J}=8 \mathrm{~Hz}, \mathrm{H}-3\right), 7.92$ (dd, $2 \mathrm{H}$, $\left.{ }^{3} J=8 \mathrm{~Hz}, \mathrm{H}-4\right), 8.69$ (s, 2H, H-6). ${ }^{13} \mathrm{C}-\mathrm{NMR}\left(\left(\mathrm{CD}_{3}\right)_{2} \mathrm{SO}, 75 \mathrm{MHz}\right.$, $298 \mathrm{~K}, 18904$ scan $), \delta$ ppm: 17.6, $24.5\left(\mathrm{CH}_{3}\right), 66.7\left(\underline{\mathrm{C}}-\mathrm{CH}_{3}\right), 88.1$ (C-7), 127.2 (C-3), 136.8 (C-4), 137.9 (C-5), 140.9 (C-2), 150.7 (C-6). MS-FD (70 eV, $\left.\mathrm{CH}_{2} \mathrm{Cl}_{2}\right) \mathrm{m} / \mathrm{z}: 496.4\left(\mathrm{M}^{+}\right), \quad \mathrm{MW}$ calculated $\mathrm{C}_{26} \mathrm{H}_{36} \mathrm{~N}_{6} \mathrm{O}_{4}\left(\mathrm{MW}^{+}\right) 496.60$.

2,2'-(5,5'-(Ethyne-1,2-diyl)bis(pyridine-2,5-diyl))bis(4,4,5,5tetramethylimidazolidine-1,3-diol) (2b). Bisimidazolidine-diol 2b was synthesized in $67 \%$ yield from dialdehyde 2 a $(0.1 \mathrm{~g}$, $0.4 \mathrm{mmol})$ and BHA (0.14 g, $0.96 \mathrm{mmol})$ following general protocol B2. ${ }^{1} \mathrm{H}-\mathrm{NMR} \S\left(\left(\mathrm{CD}_{3}\right)_{2} \mathrm{SO}, 250 \mathrm{MHz}, 298 \mathrm{~K}, 16 \mathrm{scan}\right), \delta$ ppm: 1.09 (s, 24H, $\mathrm{CH}_{3}$ ), 4.69 (s, H-7), 7.68 (d, 2H, ${ }^{3} \mathrm{~J}=8 \mathrm{~Hz}$, $\mathrm{H}-3$ ), 8.02 (dd, 2H, $\left.{ }^{3} \mathrm{~J}=8 \mathrm{~Hz}, \mathrm{H}-4\right), 8.71$ (d, 2H, H-6). MS-FD $\left(70 \mathrm{eV}, \mathrm{CH}_{2} \mathrm{Cl}_{2}\right) \mathrm{m} / \mathrm{z}: 496.1\left(\mathrm{M}^{+}\right)$, MW calculated $\mathrm{C}_{26} \mathrm{H}_{36} \mathrm{~N}_{6} \mathrm{O}_{4}$ $\left(\mathrm{MW}^{+}\right)$496.60.

2,2'-(Biphenyl-4,4'-diyl)bis(4,4,5,5-tetramethylimidazolidine1,3-diol) (3b). Compound $\mathbf{3 b}$ was synthesized in accordance with general procedure B1 from biphenyl-4,4'-dicarbaldehyde 3a $(0.305 \mathrm{~g}, 1.5 \mathrm{mmol})$ and BHA $(0.64 \mathrm{~g}, 4.3 \mathrm{mmol})$ in quantitative yield (0.65 g, 95\%). ${ }^{1} \mathrm{H}$ NMR (( $\left.\left.\mathrm{CD}_{3}\right)_{2} \mathrm{SO}, 250.13 \mathrm{MHz}\right), \delta$ ppm: 1.11 $\left(\mathrm{s}, 12 \mathrm{H}, \mathrm{CH}_{3}\right), 1.13\left(\mathrm{~s}, 12 \mathrm{H}, \mathrm{CH}_{3}\right), 4.59$ (s, 2H, N-Cㅍ-N), 7.42-7.76 $(\mathrm{m}, 8 \mathrm{H}, \mathrm{ArH}), 7.83(\mathrm{~s}, 4 \mathrm{H},-\mathrm{OH}) .{ }^{13} \mathrm{C} \mathrm{NMR}\left(\left(\mathrm{CD}_{3}\right)_{2} \mathrm{SO}, 63 \mathrm{MHz}\right.$, $298 \mathrm{~K}, 256 \mathrm{scan}), \delta$ ppm: 17.6, $24.8\left(\mathrm{CH}_{3}\right), 66.5\left(\underline{\mathrm{C}}-\mathrm{CH}_{3}\right), 90.4$ $(\mathrm{N}-\mathrm{CH}-\mathrm{N}), 126.3,129.5\left(\mathrm{CH}_{\mathrm{Ar}}\right), 139.8,141.4\left(\mathrm{C}_{\mathrm{Ar}}\right)$. MS-FD (70 eV, $\left.\mathrm{CH}_{2} \mathrm{Cl}_{2}\right) \mathrm{m} / z: 470.1\left(\mathrm{M}^{+}\right)$, MW calculated $\mathrm{C}_{26} \mathrm{H}_{30} \mathrm{~N}_{6} \mathrm{O}_{4}\left(\mathrm{MW}^{+}\right)$ 470.60 .

2,2' -(Bipyridine-1, $\mathbf{1}^{\prime}$-diyl)bis(4,4,5,5-tetramethylimidazolidine1,3-diol) (4b). Bipyridine imidazolidine $4 \mathbf{b}$ was synthesized following methodology B1. Thus, $\mathbf{4 b}$ was obtained from the reaction between bipyridine-2,2'-dicarbaldehyde 4 a (0.15 g, $0.71 \mathrm{mmol})$ and BHA $(0.28 \mathrm{~g}, 1.85 \mathrm{mmol})$ in $88 \%$ yield $(0.30 \mathrm{~g})$. ${ }^{1} \mathrm{H} \mathrm{NMR}\left(\left(\mathrm{CD}_{3}\right)_{2} \mathrm{SO}, 250.13 \mathrm{MHz}\right), \delta \mathrm{ppm}: 0.84-0.87\left(\mathrm{~d}, 24 \mathrm{H}, \mathrm{CH}_{3}\right)$, 4.40 (s, 2H, N-CH-N), 7.68 (s, 4H, -OH), 7.73-7.77 (d, 2H, ArH), 8.12-8.15 (d, 2H, ArH), 8.48 (s, 2H, ArH). $\left.{ }^{13} \mathrm{C} \mathrm{NMR} \mathrm{((CD}\right)_{2} \mathrm{SO}, 63$ $\mathrm{MHz}, 298 \mathrm{~K}, 256 \mathrm{scan}), \delta$ ppm: 17.3, $20.8\left(\mathrm{CH}_{3}\right), 66.3\left(\underline{\mathrm{C}}-\mathrm{CH}_{3}\right)$, $87.9(\mathrm{~N}-\mathrm{CH}-\mathrm{N}), 125.8,127.9,131.9\left(\mathrm{CH}_{\mathrm{Ar}}\right), 137.4,146.5\left(\mathrm{C}_{\mathrm{Ar}}\right)$. MS-FD (70 eV, $\left.\mathrm{CH}_{2} \mathrm{Cl}_{2}\right) \quad m / z: 471.8\left(\mathrm{M}^{+}\right), \quad \mathrm{MW}$ calculated $\mathrm{C}_{26} \mathrm{H}_{30} \mathrm{~N}_{6} \mathrm{O}_{4}\left(\mathrm{MW}^{+}\right) 472.28$.

2-(4-\{2-[4-(1,3-Dihydroxy4,4,5,5-tetramethyl-imidazolidine-2yl)phenyl] ethynyl\}phenyl)-4,4,5,5-tetramethyl-imidazolidine-1,3diol (5b). Following general method B1 from $0.45 \mathrm{~g}$ (1.94 mmol) of the tolane dialdehyde $5 \mathrm{a}^{11} 0.94 \mathrm{~g}$ of pale-yellow bisimidazolidine $5 \mathbf{b}$ was synthesized (98\% yield). ${ }^{1} \mathrm{H}-\mathrm{NMR}\left(\left(\mathrm{CD}_{3}\right)_{2} \mathrm{SO}\right.$, $250 \mathrm{MHz}, 298 \mathrm{~K}, 105 \mathrm{scan}$ ), $\delta$ ppm: 1.05, 1.09 (both s $12 \mathrm{H},-\mathrm{CH}_{3}$ ), 4.54 (s, 2H, C imid-2) $_{1} 7.53$ (w.s, 8H, Ar-H), 7.84 (w.s, 4H, -N-OH).

$\S$ The ${ }^{13} \mathrm{C}$-NMR spectrum of $2 \mathbf{b}$ was not obtained, as the sample appeared to be unstable in DMSO and began to oxidize in the NMR tube upon measurement. 
${ }^{13} \mathrm{C}-\mathrm{NMR}\left(\left(\mathrm{CD}_{3}\right)_{2} \mathrm{SO}, 63 \mathrm{MHz}, 298 \mathrm{~K}, 256 \mathrm{scan}\right), \delta$ ppm: 17.4, 24.5 $\left(-\mathrm{CH}_{3}\right), 66.4\left(\mathrm{C}_{\text {imid }}{ }^{-4}, \mathrm{C}_{\text {imid }}-5\right), 88.2(-\mathrm{C} \equiv \mathrm{C}-), 90.1\left(\mathrm{C}_{\text {imid }}{ }^{-2}\right), 121.6$ (Ar-C), 128.2, 131.0 (ArC-H), 143.5 (Ar-C). MS-FD (70 eV, $\left.\left(\mathrm{CD}_{3}\right)_{2} \mathrm{SO}\right)$ $m / z: 494.293\left(\mathrm{M}^{+}\right)$, MW calculated $\mathrm{C}_{28} \mathrm{H}_{38} \mathrm{~N}_{4} \mathrm{O}_{4}\left(\mathrm{MW}^{+}\right)$494.291.

C. General procedure for the oxidation of 4,4,5,5-tetramethylimidazolidine-1,3-diol derivatives to nitronyl nitroxides. A suspension of 4,4,5,5-tetramethylimidazolidine-1,3-diol $(1 \mathrm{mmol})$ in a $\mathrm{H}_{2} \mathrm{O} / \mathrm{CH}_{2} \mathrm{Cl}_{2}(1: 2)$ mixture $(\sim 50 \mathrm{~mL})$ was cooled down to $0-5{ }^{\circ} \mathrm{C}$ using an ice bath. To that mixture a $5 \%$ aqueous solution of $\mathrm{NaIO}_{4}(0.8$ eq.) was added dropwise. The progress of the reaction was monitored by $\mathrm{TLC}\left(\mathrm{SiO}_{2}\right.$, hexane/ethyl acetate or dichloromethane with $5 \%$ methanol). After the reaction was complete $(0.5-3 \mathrm{~h})$, a dark-blue organic layer was separated. The aqueous layer was extracted with dichloromethane $(3 \times 25 \mathrm{~mL})$. The combined organic extracts were additionally washed with water $(2 \times 30 \mathrm{~mL})$, brine $(1 \times 50 \mathrm{~mL})$, and dried over $\mathrm{MgSO}_{4}$ (in some cases $-\mathrm{Na}_{2} \mathrm{SO}_{4}$ ). The residue after filtration was reduced to a volume of $2 \mathrm{~mL}$, and purified on a chromatographic column $\left(\mathrm{SiO}_{2}\right.$, hexane/ethyl acetate or $\left.\mathrm{CH}_{2} \mathrm{Cl}_{2} / \mathrm{MeOH}\right)$.

2,2'-(2,2' -(Ethyne-1,2-diyl)bis(pyridine-2,5-diyl))bis(4,4,5,5-tetramethyl-4H,5H-imidazoline-1-oxyl-3-oxo) (1c). Procedure $\mathrm{C}$ and subsequent purification through a short flesh-column $\left(\mathrm{SiO}_{2}\right.$, hexane/ethyl acetate, $1: 3$ ) afforded $54 \mathrm{mg}$ of the bluish crystals of 1c $(13 \%)$. M.p.: $219-220{ }^{\circ} \mathrm{C}$. UV-Vis $\left(\mathrm{CHCl}_{3}\right) \lambda / \mathrm{nm}\left(\varepsilon, \mathrm{mol}^{-1} \mathrm{~cm}^{-1}\right)$ : 612 (808), 344 (55 554); (toluene) $\lambda / \mathrm{nm}\left(\varepsilon, \mathrm{mol}^{-1} \mathrm{~cm}^{-1}\right) 623$ (483), 345 (50402). FT-IR (solid; $\nu / \mathrm{cm}^{-1}$ ): 3108, 3072, 2986, 2939 (s, Py ${ }_{-\mathrm{C}-\mathrm{H}}$ stretching), $2144(\mathrm{w}, \mathrm{C} \equiv \mathrm{C}), 1734(\mathrm{~m}, \mathrm{C}=\mathrm{O}), 1583$ (s, $\mathrm{Py}_{\mathrm{C}}=\mathrm{C}$ stretching), 1549 (s, $\mathrm{C}=\mathrm{N}_{\text {imid }}$ ), 1347 (s, N-O). Elemental analysis: C 62.7; H 5.96; N 17.02; calculated for $\mathrm{C}_{26} \mathrm{H}_{30} \mathrm{~N}_{6} \mathrm{O}_{4}$ : C 63.66; $\mathrm{H}$ 6.16; N 17.13 .

2,2'-(5,5'-(Ethyne-1,2-diyl)bis(pyridine-2,5-diyl))bis(4,4,5,5-tetramethyl-4H,5H-imidazoline-1-oxyl-3-oxo) (2c). To a magnetically stirred solution of imidazolidine $2 \mathbf{b}(0.133 \mathrm{~g}, 0.27 \mathrm{mmol})$ in absolute methanol $(3 \mathrm{~mL})$ an excess of $\mathrm{MnO}_{2}(0.35 \mathrm{~g}, 4 \mathrm{mmol}$, 15 equivalents with respect to $\mathbf{2 b}$ ) was added. The process was monitored by TLC to avoid overoxidation, and an imino nitroxide radical formed. After the reaction was complete $\mathrm{MnO}_{2}$ was filtered off and methanol was evaporated. The radical was purified using thin-plate chromatography $\left(\mathrm{SiO}_{2}\right.$, chloroform/ethyl acetate, $\left.2: 1\right)$. After evaporation of the solvent blue crystals were obtained in $34 \%$ total yield. M.p.: $236-239{ }^{\circ} \mathrm{C}$. UV-Vis $\left(\mathrm{CHCl}_{3}\right) \lambda / \mathrm{nm}(\varepsilon$, $\mathrm{mol}^{-1} \mathrm{~cm}^{-1}$ ): 591 (503), 341 (38 929). FT-IR (powder, $\nu / \mathrm{cm}^{-1}$ ): 3048, 2985, 2933, 2868 (s, Py-C-H stretching), 2141 (w, C $\equiv \mathrm{C}$ ), $1733(\mathrm{~m}, \mathrm{C}=\mathrm{O}), 1588\left(\mathrm{~m}, \mathrm{Py}_{\mathrm{C}=\mathrm{C}}\right.$ stretching), $1560\left(\mathrm{~s}, \mathrm{C}=\mathrm{N}_{\text {imid }}\right)$, 1360 (s, N-O). Elemental analysis: C 63.1; H 6.22; N 16.62; calculated for $\mathrm{C}_{26} \mathrm{H}_{30} \mathrm{~N}_{6} \mathrm{O}_{4}$ : C 63.66; $\mathrm{H}$ 6.16; N 17.13.

D. General procedure for the oxidation of 4,4,5,5-tetramethylimidazolidine-1,3-diol derivatives to imino nitroxides. To a magnetically stirred solution of imidazolidine $(1 \mathrm{mmol})$ in nitromethane $(12 \mathrm{~mL}) \mathrm{MnO}_{2}(14 \mathrm{mmol})$ was added. After $\sim 35$ minutes of stirring at room temperature the oxidant was filtered off and washed carefully with small portions of ethyl acetate on a filter. The filtrate was diluted with toluene $(12 \mathrm{~mL})$ and concentrated to a volume of $c a .2 \mathrm{~mL}$ in vacuo. The residue was placed on a column wetted with toluene, and eluted with an ethyl acetate/hexane mixture.
2,2'-(2,2'-(Ethyne-1,2-diyl)bis(pyridine-2,5-diyl))bis(4,4,5,5-tetramethyl-4H,5H-imidazoline-1-oxyl) (1d). Compound 1d was synthesized as described in protocol D from imidazolidine $\mathbf{1 b}(0.47 \mathrm{~g}$, $0.95 \mathrm{mmol}$ ) using $\mathrm{MnO}_{2}(1.23 \mathrm{~g}, 14.1 \mathrm{mmol})$ in $61 \%$ yield (250 mg). M.p.: compound decomposed at $195{ }^{\circ} \mathrm{C}$. UV-Vis (toluene) $\lambda / \mathrm{nm}\left(\varepsilon, \mathrm{mol}^{-1} \mathrm{~cm}^{-1}\right): 467$ (944), 326 (35 207). FT-IR (powder, $\nu / \mathrm{cm}^{-1}$ ): 3067, 2969, 2924 (s, Py ${ }_{-\mathrm{C}-\mathrm{H}}$ stretching), 2136 (w, C $\equiv \mathrm{C}), 1591$ ( $\mathrm{s}, \mathrm{Py}_{\mathrm{C}=\mathrm{C}}$ stretching), $1555\left(\mathrm{~s}, \mathrm{C}=\mathrm{N}_{\text {imid }}\right)$, 1368 (m, N-O). Elemental analysis: C 67.6; H 6.43; N 18.07; calculated for $\mathrm{C}_{26} \mathrm{H}_{30} \mathrm{~N}_{6} \mathrm{O}_{2}$ : C 68.10; $\mathrm{H} 6.59 ; \mathrm{N} 18.30$.

2,2' -(Biphenyl-4,4' -diyl)bis (4,4,5,5-tetramethylimidazolidine1-oxyl) (3d). Oxidation of precursor $3 \mathbf{b}(0.3 \mathrm{~g}, 0.64 \mathrm{mmol})$ with excess of $\mathrm{MnO}_{2}(0.83 \mathrm{~g}, 9.5 \mathrm{mmol})$ according to methodology D was complete in 20 minutes. Radical 3d was purified on a chromatographic column with a hexane/ethyl acetate gradient solvent mixture $(5: 1,3: 1)$. The yield of orange crystals of $\mathbf{3 d}$ was $0.14 \mathrm{~g}$ (47\%). M.p.: $248.5-250{ }^{\circ} \mathrm{C}$. UV-Vis $\left(\mathrm{CHCl}_{3}\right) \lambda / \mathrm{nm}$ $\left(\varepsilon, \mathrm{mol}^{-1} \times \mathrm{cm}^{-1}\right): 461$ (1090), 486 (1016). FT-IR (powder, $\left.\nu / \mathrm{cm}^{-1}\right)$ : 3069, 2973, 2926, 2862 (s, Ph-C-H stretching), 1611 (s, Ph $\mathrm{C}=\mathrm{C}$ stretching), $1567(\mathrm{w}, \mathrm{C}=\mathrm{N}), 1364(\mathrm{~s}, \mathrm{~N}-\mathrm{O})$. Elemental analysis: $\mathrm{C}$ 71.86; $\mathrm{H}$ 7.32; $\mathrm{N}$ 12.66; calculated for $\mathrm{C}_{26} \mathrm{H}_{32} \mathrm{~N}_{4} \mathrm{O}_{2}$ : C 72.19; H 7.46; N 12.95 .

2,2' -(Bipyridine-1, $\mathbf{1}^{\prime}$-diyl)bis (4,4,5,5-tetramethylimidazolidine1-oxyl) (4d). The titled biradical 4d was achieved using a procedure similar to the one described above in $44 \%$ yield. M.p.: compound began to decompose at $253{ }^{\circ} \mathrm{C}$. UV-Vis $\left(\mathrm{CHCl}_{3}\right)$ $\lambda / \mathrm{nm}\left(\varepsilon, \mathrm{mol}^{-1} \mathrm{~cm}^{-1}\right): 448$ (625), 476 (548). FT-IR (powder, $\nu / \mathrm{cm}^{-1}$ ): 3087, 3043, 2981 (s, Py ${ }_{-\mathrm{C}-\mathrm{H}}$ stretching), 1603 (s, $\mathrm{Py}_{\mathrm{C}}=\mathrm{C}$ stretching), 1562 (s, $\left.\mathrm{C}=\mathrm{N}_{\text {imid }}\right), 1366$ ( $\left.\mathrm{s}, \mathrm{N}-\mathrm{O}\right)$. Elemental analysis: C 65.36; $\mathrm{H}$ 7.02; N 19.11; calculated for $\mathrm{C}_{24} \mathrm{H}_{30} \mathrm{~N}_{6} \mathrm{O}_{2}$ : C 66.34; $\mathrm{H}$ $6.96 ; \mathrm{N} 19.34$.

2-(4-\{2-[4-(1-Oxyl-4,4,5,5-tetramethyl-4H,5H-imidazolin-2-yl)phenyl]-ethynyl\}phenyl)-4,4,5,5-tetramethyl-imidazoline-1-oxyl3-oxo (5d). Compound 5d was synthesized from precursor 5b (0.27 g, $0.55 \mathrm{mmol}$ ) employing an excess of $\mathrm{MnO}_{2}(0.7 \mathrm{~g}$, $8.05 \mathrm{mmol}$ ) as described in more detail in general procedure C. Isolation of product 5d using a chromatographic column with silica gel and a hexane/ethyl acetate $(3: 2)$ eluent mixture afforded red crystals of 5d in 58\% total yield. M.p.: compound began decomposing above $195{ }^{\circ} \mathrm{C}$. UV-Vis (toluene) $\lambda / \mathrm{nm}$ $\left(\varepsilon, \mathrm{mol}^{-1} \mathrm{~cm}^{-1}\right): 467$ (944), 326 (35 207). FT-IR (powder, $\left.\nu / \mathrm{cm}^{-1}\right):$ 3067, 2969, 2924 (s, Py ${ }_{-\mathrm{C}-\mathrm{H}}$ stretching), $2136(\mathrm{w}$, $\mathrm{C} \equiv \mathrm{C}$ ), 1591 ( $\mathrm{s}, \mathrm{Py}_{\mathrm{C}=\mathrm{C}}$ stretching), $1555\left(\mathrm{~s}, \mathrm{C}=\mathrm{N}_{\mathrm{imid}}\right), 1368$ (m, N-O). Elemental analysis: $\mathrm{C} 73.15 ; \mathrm{H}$ 6.76; N 12.11; calculated for $\mathrm{C}_{28} \mathrm{H}_{32} \mathrm{~N}_{4} \mathrm{O}_{2}$ : C 73.66; $\mathrm{H}$ 7.06; N 12.27.

\section{Conclusion}

We have demonstrated that the synthesis and study of structurally similar compounds exhibiting different magnetic behaviors provide a reasonable approach for understanding the relationship between the substituents in the aromatic ring and the intramolecular exchange constant $J_{\text {intra. }}$ Unfortunately, the magnetic interactions based on structural peculiarities are difficult to predict as their strength strongly depends on the relative orientation 
between the interacting magnetic orbitals. Here, the torsion angles $\theta$ have crucial impacts on the overall $\pi$-conjugation in the nitroxide biradical systems. The latter in turn is responsible for the efficient communication between the nitroxide fragments. The crystal structure analysis shows that the synthesized biradicals are planar with relatively small torsions between the radical fragments and the aromatic bridges (with an exception in the case of derivative 2c). These are the essential prerequisites for obtaining a weak intramolecular coupling. A rapid increase of the torsion hinders the conjugation within the biradical system 2c, decreasing the intramolecular exchange interactions within the molecule. This structural feature causes an enhancement of the intermolecular coupling within 2 c. As a result, an unprecedentedly high value of the coupling constant is observed in NN biradical 2c. This work illustrates the difficulties in the design and prediction of a target structure, and the need for an experimental proof.

Magnetic measurements, carried out on single-crystalline samples, confirmed that for biradicals 1c, 1d, 3d, 4d and 5d, weak antiferromagnetic intramolecular interactions are predominant. According to the magnetic characterization studied $\pi$-bridged nitroxides possess a moderate intra-dimer coupling in the range -2 to $-6 \mathrm{~K}$ as derived from the fits based on an isolated dimer model. Furthermore, magnetic measurements and their interpretation revealed that $\mathrm{NN}$ biradical 2c exhibits surprisingly strong antiferromagnetic interactions, owing to the short $(\sim 3.5 \AA)$ interdimer interaction. IN biradical 5d features a field-induced ordered phase assigned to $3 \mathrm{D}$ interdimer couplings, which accounts for a description in terms of a BEC of triplons.

In summary, we have found promising candidates in the quest for purely organic molecular magnets and crystalline networks with higher ordering.

\section{Conflicts of interest}

There are no conflicts to declare.

\section{Acknowledgements}

We wish to thank Dr Dieter Schollmeyer (Johannes GutenbergUniversity Mainz) and Dr Volker Enkelmann for crystallographic data analysis. The authors are pleased to acknowledge continued support from the Max Planck Society and the DFG-SFB TR49. Open Access funding provided by the Max Planck Society.

\section{Notes and references}

1 S. Sachdev, Nat. Phys., 2008, 4, 173.

2 T. Giamarchi, Ch. Rüeggv and O. Tchernyshyov, Nat. Phys., 2008, 4, 198-204.

3 C. Rüegg, K. Kiefer, B. Thielemann, D. F. McMorrow, V. Zapf, B. Normand, M. B. Zvonarev, P. Bouillot, C. Kollath, T. Giamarchi, S. Capponi, C. Poilblanc, D. Biner and K. W. Krämer, Phys. Rev. Lett., 2008, 101, 247202.

4 U. Tutsch, B. Wolf, S. Wessel, L. Postulka, Y. Tsui, H. O. Jeschke, I. Opahle, T. Saha-Dasgupta, R. Valenti,
A. Brühl, K. Removic-Langer, T. Kretz, H.-W. Lerner, M. Wagner and M. Lang, Nat. Commun., 2014, 5, 5169.

5 J. Veciana, J. Cirujeda, C. Rovira, E. Molins and J. J. Novoa, J. Phys., 1996, 6, 1967.

6 H. Sasaki, L.-R. Lin, T. Yokoyama, M. D. Sevilla, V. N. Reddy and F. J. Giblin, Invest. Ophthalmol. Visual Sci., 1998, 39, 544.

7 W. Bi, J. Cai, Y. Zhang, S. Liu, S. A. Green and L. Bi, Bioorg. Med. Chem. Lett., 2008, 18, 1788.

8 M. C. Krishna and W. DeGraff, J. Med. Chem., 1998, 41, 3477.

9 J. H. Osiecki and E. F. Ullman, J. Am. Chem. Soc., 1968, 90, 1078.

10 A. Caneschi, D. Gatteschi, P. Rey and R. Sessoli, Inorg. Chem., 1988, 27, 1756; A. Caneschi, D. Gatteschi, R. Sessoli and P. Rey, Acc. Chem. Res., 1989, 22, 392.

11 Y. B. Borozdina, E. A. Mostovich, V. Enkelmann, B. Wolf, P. T. Cong, U. Tutsch, M. Lang and M. Baumgarten, J. Mater. Chem. C, 2014, 2, 6618.

12 K. Yamaguchi, M. Okumura, J. Maki, T. Noro, H. Namimoto, M. Nakano, T. Fueno and K. Nakasuji, Chem. Phys. Lett., 1992, 190, 353.

13 G. Seber, R. S. Fretas, J. T. Mague, A. Paduan-Filho, X. Gratens, V. Bindilatti, N. F. Oliveira Jr., N. Yoshioka and P. M. Lahti, J. Am. Chem. Soc., 2012, 134, 3825.

14 G. Zoppellaro, A. Geies and M. Baumgarten, Eur. J. Org. Chem., 2004, 2367.

15 E. Mostovich, Y. Borozdina, V. Enkelmann, K. RemovićLanger, B. Wolf, M. Lang and M. Baumgarten, Cryst. Growth Des., 2012, 12, 54.

16 S. Takahashi, Y. Kuroyama, K. Sonogashira and N. Hagihara, Communications, 1980, 627.

17 C. Bolm, M. Ewald, M. Felder and G. Schlinglo, Chem. Ber., 1992, 125, 1169.

18 F. C. Alderweireldt, I. Vrijens, E. L. Esmans and E. D. Clercq, Nucleosides Nucleotides, 1989, 8, 891.

19 J. Wicha and M. Masnyl, Heterocycles, 1981, 16, 521.

20 F. J. Romero-Salguero and J.-M. Lehn, Tetrahedron Lett., 1999, 40, 859.

21 X. Wang, P. Rabbat and P. O'Shea, Tetrahedron Lett., 2000, 41, 4335.

22 A. Landa, A. Minkkila and G. Blay, Chem. - Eur. J., 2006, 12, 3472.

23 M. A. Peterson and J. Mitchell, J. Org. Chem., 1997, 62, 8237. 24 T. W. Greene and P. G. Wuts, Protective groups in organic synthesis, 1991.

25 F. Ebmeyer and F. Vögtle, Chem. Ber., 1989, 122, 1725.

26 I. Karamé, M. Jahjah and M. Lemaire, Tetrahedron: Asymmetry, 2004, 15, 1569.

27 R. Ziessel and G. Ulrich, J. Mater. Chem., 1999, 9, 1435.

28 E. V. Tretyakov, S. Tolstikov and A. Mareev, Eur. J. Org. Chem., 2009, 2548.

29 E. V. Tretyakov and V. I. Ovcharenko, Russ. Chem. Rev., 2009, 78, 971.

30 E. Önal, Y. Yerli, B. Cosut, G. Pilet, V. Ahsen, D. Luneau and C. Hirel, New J. Chem., 2014, 38, 4440.

31 DFT calculations were carried out using Gaussian 09, B3LYP hybrid functionals for geometry optimization and the BLYP 
functional for energy calculation of broken symmetry $v s$. triplet states together with 6-31g(d) basis sets. See M. J. Frisch et al. Gaussian 09, Revision D.01, Gaussian, Inc., Wallingford CT, 2013.

32 M. E. Ali and S. N. Datta, J. Phys. Chem. A, 2006, 110, 2776. 33 O. Kahn, Molecular Magnetism, VCH, Weinheim-New York, 1993.
34 B. Bleaney and D. K. Bowers, Proc. R. Soc. London, Ser. A, 1952, 214, 451.

35 T. Mitsumori, K. Inoue, N. Koga and H. Iwamura, J. Am. Chem. Soc., 1995, 117, 2467.

36 R. Akabane, M. Tanaka, K. Matsuo, N. Koga, K. Matsuda and H. Iwamura, J. Org. Chem., 1997, 62, 8854. 